\title{
Free Space Optical Technologies
}

\author{
Davide M. Forin, G. Incerti \\ University of Rome Tor Vergata -Italy \\ G.M. Tosi Beleffi \\ ISCOM, Italian Ministry of Economic Development Comm. Department, Rome - Italy \\ A.L.J. Teixeira, L.N. Costa, P.S. De Brito Andrè \\ Instituto de Telecomunicações, Aveiro, Portugal \\ B. Geiger, E. Leitgeb and F. Nadeem \\ Graz University of Technology
}

\section{Introduction (D. Forin - G.M. Tosi Beleffi - B. Geiger - E. Leitgeb)}

Free Space Optics (FSO), also known as Optical Wireless or Lasercom (i.e. Laser Communications), is a re-emerging technology using modulated optical beams to establish short, medium or long reach wireless data transmission. Most of the attention on FSO communication systems it was initially boost by military purposes and first development of this technology was dedicated to the solution of issues related to defense applications.

Today's market interest to FSO refers to both civil and military scenarios covering different situations and different environments, from undersea to space. In particular, due to the high carrier frequency of $300 \mathrm{THz}$ and the consequently high bandwidth, the most prominent advantage of Free Space Optical (FSO) communication links may be their potential for very high data rates of several Gbps (up to $40 \mathrm{Gbps}$ in the future (J. Wells, 2009)). Other advantages like license-free operation, easy installation, commercial availability, and insensitivity to electromagnetic interference, jamming, or wiretapping make FSO interesting for applications like last mile access, airborne and satellite communication (L. Stotts et alt, 2009), temporary mobile links and permanent connections between buildings. Mainly, the adoption of FSO is needed when a physical connection is not a practicable solution and where is requested to handle an high bandwidth. As a matter of fact, FSO is the only technology, in the wireless scenario, able to grant bandwidth of several Gigabits per second. The interest in this technology is also due to the low initial CAPEX (Capital Expenditure) requirement, to the intrinsic high-level data protection \& security, to the good flexibility and great scalability innate in this solution. For these reasons FSO possible applications cover today, as mentioned, a wide range. Thus this technology generates interest in several markets: the first/last mile in dense urban areas, network access for isolated premises, highspeed LAN-to-LAN (Local Area Networks) and even chip-to-chip connections, transitional and temporary network connection, undersea and space communication. Furthermore FSO can be used as an alternative or upgrade add-on to existing wireless technologies when the climatic conditions permit its full usage. 
In spite of the growing interest in space and undersea applications, infact, the terrestrial FSO still remains of primary significance and the performance of such links is highly dependent on different weather conditions. Atmospheric effects affect the distance and the availability of the optical wireless links so not all the geographical sites are suitable for this kind of broadband solution. Links as long as $7 \mathrm{~km}$ are in operation, but prior to the deployment of wireless optical links the average weather condition must be evaluated to estimate the expected outage time on the link in that area. The outage will depend on the link length and on the persistence of adverse weather conditions. So in general, it can be affirmed that short enough links, hundreds of meters, will be operational also with the worst possible weather conditions.

Besides commercially available opaque systems, where the optical signal is terminated to an electronic receiver and subsequently sent through the atmosphere by means of a dedicated laser, a new configuration, known as fully transparent, is under study. The bandwidth achievable in these last systems is comparable to the optical fiber one. Being absent any kind of optical to electrical bottleneck (OEO). For transparency, infact, is meant launching and collecting power directly through single mode optical fibers. Such new extremely high bandwidth wireless systems, although still in the research stage, are gaining more and more interest especially in the last mile scenarios. Last but not least, compared to a microwave link, an FSO link can support higher bit rates and its operational frequencies are license-free in all jurisdictions apart for an year low cost fee that must be paid to the reference PA (Public Administration). The Authors want to outline that the work carried out in this chapter has been done in the framework of the European funded FP7 NoE BONE Project (WP13) and the COST IC0802 Action.

\section{History of Free Space Communications (G.M. Tosi Beleffi)}

Telegraphy is a word coming from ancient greek and means in Italian "scrivere a distanza" while in English sounds more or less like "writing to a distant place". The human being has from the very beginning tried to increase his capabilities to communicate with his far away fellow men and so to transmit. Under this point of view, the mythology is full of interesting examples with the most famous and known that is Ermes, the Gods messenger, able to move faster than the wind and responsible to carry informations to the Gods.

First experiences in the ancient past can be found in the IVth century b.C. (before Christ), where Diodoro Crono reports on a human chain used by the Persian king Dario I (522-486 b.C) to transmit informations from the Capital to the Empire's districts.

In the IVth Century b.C., Enea il Tattico, reports on an hydraulic telegraph probably invented by the Chartaginians. During the Roman and Greek age, was used to place in geographical key points "fire towers" to be switched on in case of security breachs and/or attacks on the borders. Eschilo (525-456 a.C.) reports in the Orestea that the news about the falls of Troy arrived to Argo passing through the Cicladi islands covering, more or less, 900 $\mathrm{km}$ (Eschilo, 458 b.C.). This sort of tradition remained, for example, on the Italian territory assuming and adopting different schemes, fire or mechanical systems, depending on the time period, the geography and the geopolicy (Pottino, 1976).

In the Center-South of Italy, in particular, the use of fire based signals during night and of smoke based signals during the daylight on the top of towers or hills, afterwards called communications by the usage of fani, has been quite common in the XVI and XVII Centuries 
a.C. (Agnello, 1963). During the day one smoke signal means the presence of one enemy vessel, in the night was switched on a bundle of dry woods and moved up and down to inform about the exact number of the enemy vessels. Several testimonies report on different communications links and distances. The most interesting one has been established in 1657 between the city of Messina and the Malta island with mid span vessels used to cover the Mediterranean sea (Castelli, 1700).

The use of mechanical systems to implement optical wireless systems is due to Claude Chappe in 1792 (Huurdeman, 2003). Chappe introduces the "optical telegraph" in France. The system was based on a regulator, $4.5 \mathrm{~m}$ long and $0.35 \mathrm{~m}$ wide, to which two indicators were attached. This systems was placed on the top of stations in LOS (Line Of Site) at $9 \mathrm{~km}$ each. Telescopes and human repeaters were, of course, needed to move the regulator and the indicators via three cranks and wire ropes. The time usage was short because the system was able to work only during the daylight and with good weather conditions. On the other hand, it was long reach considering an average coverage in France equal to around $4830 \mathrm{~km}$, with 29 cities connected using around 540 towers. Security was ensured by transmitting secret codes with short preambles, this also to understand the accuracy of the transmission. Chappe introduced, infact, a particular code in 1795, to increase the transmission speed. This system helped to reduced the time to exchange informations from several days to minutes and has been adopted in 1794 . The subsequent studies on the electricity, the results from Volta (1745-1827) and from Ampere (1775-1836) on the electrical pile and the introduction of the electrical telegraph in 1838 (Morse), will carry to the dismission of the Chappe system around the mid of 1800. The Chappe system was introduced also in other European countries connecting the cities of Amsterdam, Strasbourg, Turin, Milan and Brussels.

At the end of the 19th century, Alexander Graham Bell experienced with excellent results the so called Photophone (Michaelis, 1965) (Bova and Rudnicki, 2001). This system worked using the sound waves of the voice to move a mirror, responsible to send pulses of reflected sunlight to the receiving instrument. In particular Bell modulated with his voice, by the use of an acousto-optic transducer, a lens-collimated solar beam. Bell used to consider this invention to be his best work, even better than "his demonstration of the telephone". Although Bell's Photophone never became a commercial reality, it demonstrated the basic principle of optical communications.

Wireless Optical Communications, becomes from this point and year by year more important boosting the research worldwide. We can in this case divide the wireless optical experiments in three main areas depending on the time periods: in the 60s arrives the laser concepts and rises up the idea of wireless communications, in the 90s becomes popular the idea of ground to satellite and satellite to ground laser communications still using red and green sources, after 2000 the explosion of the Free Space Optical technologies (FSO) faces civil and military applications ranging from standard telecommunications up to intersatellites \& interplanets experiments and using different wavelengths from 1 up to 10 microns.

For these reasons, essentially all of the engineering of today's FSO communications systems, has been studied over the past 40 years, at the beginning for defense applications and afterwards for civil ones. By addressing the principal engineering challenges FSO, this aerospace/defense activity established a strong foundation upon which today's commercial FSO systems. 
In particular, the realization of the first LASER, based on ruby, in 1960 by Maiman opened wider possibilities for the communications involving beams propagating over long distances in atmosphere. Low loss optical fibers (less than $20 \mathrm{~dB} / \mathrm{km}$ ), infact, will arrive only in the 70s. In 1960s NASA started to perform preliminary experiments between the Goddard Space Center and the Gemini 7 module. In 1968 the first experiment about FSO transmission of 12 phone channels along $4 \mathrm{~km}$ had been demonstrated in Rome (Italy) by researchers from the Istituto P.T, CNR and Fondazione Ugo Bordoni under the management of Prof. Sette, Phisic Insitute University La Sapienza. A red laser source (0.8 microns) was used to connect two buildings between the Colombo and Trastevere Streets in Rome (Unknown, 1968). In the same year Dr. E. Kube in Germany published on the viability of free space optical communications considering both green ( 0.6 microns) and red (0.8 microns) laser sources (Kube, 1968). The introduction of semiconductor light sources working at room temperature, by Alferov in 1970, were decisive for a further development of integrated and low cost FSO systems. On the point of view of the research, the first experiment using a quantum cascade laser (Capasso 1994) can be considered fundamental today speaking about new transmission wavelengths for FSO (up to 10 microns). Between 1994 and 1996 years the first demonstration of a bidirectional space to ground laser link between the ETS-VI satellite and the Communications Research Laboratory (CRL) in Koganey (Tokio) has been accomplished. $1 \mathrm{Mbps}$ using 0.5 microns and 0.8 microns emitting lasers. With the ongoing intensive and worldwide studies on FSO communications, especially re started after the September 11 tragedy where the communications were supported by free space optics links, the related scenarios changed extremely fast covering today different applications and environments like the followings: atmosphere, undersea, inter satellites, deep space. We can infact report on the SILEX experiment (Semiconductor Intersatellite Link Experiment) in 2001 demonstrating bidirectional GEO-LEO and GEO-ground communications. ARTEMIS satellite (GEO) using a semiconductor laser at 0.8 microns directly driven at $2 \mathrm{Mbps}$ with an average output of $10 \mathrm{~mW}$ towards a Si-APD on SPOT-4 satellite (LEO). In the same year, the GeoLite (Geosyncronous Lightweight Technology Experiment) experiment successfully demonstrated a bidirectional laser communication between GEO satellites, ground and aircraft. We cannot forget afterwards the MLCD (Mars Laser Communication Demonstration) program started in 2003 and ended in 2005 with the aim of covering the distance between Earth and Mars planets using an optical parametric amplifier with an average output of $5 \mathrm{~W}$ and photon counting detectors working at 1.06 microns (Majumdar and Ricklin, 2008).

\section{Basic principles of the optical wireless communications (E. Leitgeb - B. Geiger - F. Nadeem - A.L.J. Teixeira, P. Andre)}

\subsection{Introduction}

Free Space Optical communication links transmit information by laser light through an atmospheric channel. Relying on infrared light, these communication systems are immune to electromagnetic interference (EMI), jamming, or wiretapping. Furthermore, they do not cause EMI themselves and operate at frequency bands (around $300 \mathrm{THz}$ ) were the spectrum is unlicensed. As a further advantage, FSO and fiber equipment can be combined without intermediate conversion, since both the air and the material used for fiber cables have good transmittance at the established wavelengths, namely $850 \mathrm{~nm}$ and $1550 \mathrm{~nm}$. Currently, all- 
optical fiber/FSO systems are a well populated field of research, developing solutions for signal regeneration, transmission, and reception without an intermediate electronic signal. FSO systems can be installed faster and cheaper than their wireless radio counterparts, making them interesting for short-term installations for events, military purposes and disaster recovery. Consequently, a multitude of FSO equipment is commercially available for interconnection with standard fiber or Ethernet components. Acting as an alternative to other wireless radio or high-bandwidth wired links (fiber optics, Gigabit Ethernet), it has to fulfill general requirements such as low bit error rate $(B E R<10-9)$ and high reliability.

As already mentioned, a prerequisite for these requirements is an unobstructed line-of-sight, especially in long-distance outdoor environments. A major drawback therefore is the susceptibility of FSO links to certain weather conditions, where especially fog causes severe attenuation of the laser beam and subsequent total link loss. Even moderate continental fog can result in an attenuation of $130 \mathrm{~dB} / \mathrm{km}$, whereas dense maritime fog can account for attenuations up to $480 \mathrm{~dB} / \mathrm{km}$ (E. Leitgeb et alt, 2006; M.S. Awan et alt, 2008).

Rain attenuation has very little effects on the availability of FSO systems, but these effects strongly depend on the rain rate R. According to (T. Carbonneau and D. Wisley, 1998) and the references therein an adequate relationship between rainfall and attenuation would be

$$
\begin{gathered}
\tau_{\text {rain }}=\exp (-(0.05556+0.00848 \cdot R \\
\left.\left.-3.66 \times 10^{-5} \cdot R^{2}\right) \cdot l\right)
\end{gathered}
$$

For light to moderate rain rates of $\mathrm{R}=5 \mathrm{~mm} / \mathrm{h}$ as they are occurring in the continental climate of middle Europe the attenuation is only approx. $3 \mathrm{~dB} / \mathrm{km}$. Peak attenuations due to tropical rain falls of $R=100 \mathrm{~mm} / \mathrm{h}$ would result in higher attenuations (approx. $30 \mathrm{~dB} / \mathrm{km}$ ), but such weather conditions occur rarely and only in burst in Europe and the United States (J. Wells, 2009; H.Alma and W. Al-Khateeb, 2008). Similar considerations hold for heavy snowfall (more than $5 \mathrm{~cm}$ over $3 \mathrm{hrs}$ ), where attenuations of more than $45 \mathrm{~dB} / \mathrm{km}$ have been measured (R. Nebuloni and C. Capsoni, 2008). Depending on seasonal and geographic peculiarities, these values can vary to some extent. It may also happen that certain weather events occur simultaneously, i.e. heavy rain in combination with fog, or fog in combination with snowfall (V. Kvicera, 2008).

Another phenomenon occurring influencing FSO communication links is related to scintillations and air turbulences. Air cells with different temperatures randomly distributed along the link cause focusing and defocusing of the link due to changes in the refractive index. Amplitude and frequency of these scintillation depend on the size of cells compared to the diameter of the optical beam (S. S. Muhammad, 2005; A. Chaman Motlagh, 2008). FSO systems usually cope with such variations in the optical received signal strength (ORSS) by using multiple beams (so-called multi-beam systems) or by using saturated amplifiers (M. Abtahi and L. Rusch, 2006). More detailed investigations can be found in (S. S. Muhammad, 2005) and the references there.

Other problems affecting visibility are mostly related to the narrow beam FSO systems use (usually at the order of a few milli radians): sand, dust, birds, et cetera flying through the beam cause momentary link losses, whereas misalignment due to tower sway or thermal effects can be coped by auto-tracking systems (J. Wells, 2009). The sun itself acts as a noise source, which may completely overdrive the receivers (W. Kogler, 2003) if they are directly exposed to sunlight. Soiling and aging of the components, especially lenses and mirrors, 
finalize the list of effects on FSO link availability. Summarizing, most of these effects can be overcome by either granting a certain link margin (snow and rain attenuation, fluctuations due to scintillation) or by adding complexity to the system (multi-beam and auto-tracking systems). Fog, on the other hand, is the only remaining condition harmful for availability, making carrier class availability (99.999\%) for FSO systems highly questionable.

Depending on the geographic areas, fog mainly occurs during fall and winter months on a persistent basis, whereas outages during summer and spring are caused by thunderstorms (E. Leitgeb, 2004). Fig. 1 shows the average unavailability throughout the year in Graz, Austria. Moreover, diurnal changes affect the probability of fog as Fig. 2 shows; it is low during noon where the sun clears up the sky and high during dusk, dawn and the night (E. Leitgeb, 2004).

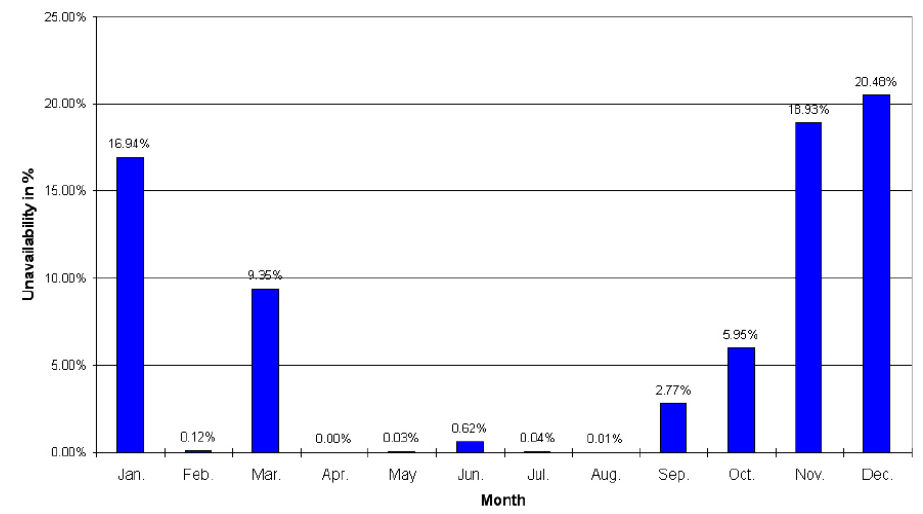

Fig. 1. Average unavailability throughout the year (based on measurements from Oct. 2000 to Sep. 2001 (with the permission of E. Leitgeb, 2004))

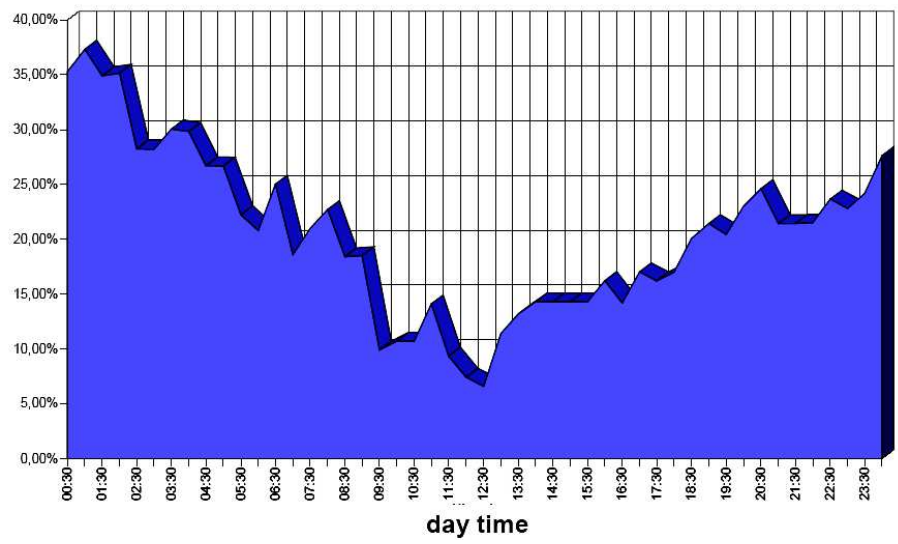

Fig. 2. Probability of failure during the daytime (based on measurements from Dec. 2000 (with the permission of E. Leitgeb, 2004))

Due to the complexity connected with phase or frequency modulation, current free-space optical communication systems typically use intensity modulation with direct detection 
(IM/DD). Like in fibre optics communications systems, the performance characteristics for a free space optical communications system are dependent on the propagation medium. However, in this case the propagation medium is randomly changed, and susceptible to atmospheric conditions, resulting in alterations to the beam propagation constants.

In order to get a clearer picture of the behavior of FSO systems a numerical model for the atmosphere is going to be presented [Andre, 2003]. This propagation model was incorporated in a commercial available photonic simulator and used to predict the behaviour of a point to point free space data link as function of the climacteric variables.

\subsection{Atmosphere Model}

As, referred, atmospheric effects can degrade free space data links by two mechanisms: (i) reduction in the detected optical power level due to atmospheric attenuation and (ii) random optical power fluctuations in the received beam which result in beam deformation, scintillation effects and beam wander (Kim, 1998). All these factors can become impairing to the communications if their influence is significant. For that it is going to be presented each of the contributing parts model and therefore a complete evaluation with effects will be made for better understanding of the real effects in the system.

\section{A. Atmospheric attenuation}

The atmospheric attenuation results from the interaction of the laser beam with air molecules and aerosols along the propagation. Similar to other waves, the optical beam power has an exponential decay with propagation distance. At a given distance from the emitter, $l$, the optical transmittance is:

$$
\tau=\tau_{a}+\tau_{s}=\frac{P(l)}{P(0)}=\exp (-\alpha \cdot l)
$$

where $\alpha$ is the overall attenuation coefficient, determined by four individual processes: molecular absorption, molecular scattering, aerosol absorption and aerosol scattering.

The molecular absorption includes the absorption by water, $\mathrm{CO} 2$ and ozone molecules. The aerosol absorption results from the finely dispersed solid and liquid particles in the atmosphere, such as ice and dust, with a maximum radius of $20 \mu \mathrm{m}$. A simple approach to calculate absorption, assumes that variations in the transmission are caused by changes in the water content of the air. The precipitable water, $w$ (in millimetres), encountered by the light beam is (Wichel, 1990):

$$
w=10^{-3} \cdot \rho \cdot l
$$

where $\rho$ is the absolute humidity in $\mathrm{g} / \mathrm{m} 3$. This value can be related with the relative humidity percentage $(\mathrm{RH})$ and with the temperature in degrees Celsius, $T$, by:

$$
\begin{gathered}
\rho=R H \cdot(-0.74+90.96 \cdot \exp (T / 13.67) \ldots \\
-85.4 \cdot \exp (T / 13.52))
\end{gathered}
$$

The absorptive transmittance can be then calculated for any transmission window, by the following empirical expressions (Wichel, 1990): 


$$
\begin{gathered}
\tau_{a}=\exp \left(-A_{i} \cdot w^{1 / 2}\right), \quad w<w_{i} \\
\tau_{a}=k_{i} \cdot\left(\frac{w_{i}}{w}\right)^{\beta_{i}}, \quad w>w_{i}
\end{gathered}
$$

The values typical values of the constants used are listed in table 1 (these are also used in calculations following).

\begin{tabular}{|l|l|l|l|l|}
\hline $\begin{array}{l}\text { Window } \\
\text { boundaries } \\
(\mathrm{nm})\end{array}$ & $\mathrm{Ai}$ & $\mathrm{ki}$ & $\beta \mathrm{i}$ & $\mathrm{Wi}$ \\
\hline $720-940$ & 0.0305 & 0.800 & 0.112 & 54 \\
\hline $940-1130$ & 0.0363 & 0.765 & 0.134 & 54 \\
\hline $1130-1380$ & 0.1303 & 0.830 & 0.093 & 2 \\
\hline $1380-1900$ & 0.211 & 0.802 & 0.111 & 1.1 \\
\hline $1900-2700$ & 0.350 & 0.814 & 0.1035 & 0.35 \\
\hline $2700-4300$ & 0.373 & 0.827 & 0.095 & 0.26 \\
\hline $4300-6000$ & 0.598 & 0.784 & 0.122 & 0.165 \\
\hline
\end{tabular}

Table 1. Constants used in expressions (4) and (4a).

Another attenuation process is the scattering, where there is no power loss, and there is only a directional distribution. The two dominate scattering mechanisms are the Rayleigh scattering, when the wavelength of the light is higher than the particle size, and the Mie scattering when the particle size is comparable with the wavelength of the radiation. An empirical relationship sometimes used to describe the scattering transmittance is [Wichel, 1990]:

$$
\tau_{s}=\exp \left(-l \cdot\left(C_{1} \cdot \lambda^{-\delta}+C_{2} \cdot \lambda^{-4}\right)\right)
$$

where, $C_{1}$ and $\delta$ are constants determined by the aerosol concentration and size distribution and $C_{2}=0.00258 \mathrm{~m} 3$ accounts the Rayleigh scattering. These two constants can be related with the visual range, $V$, in kilometres at $550 \mathrm{~nm}$ [1]:

$$
C_{1}=\frac{3.91}{V} \cdot 0.55^{\delta}
$$

For a very good visibility, $\delta$ can take a value of 1.6 , and for average visibility it have a value of $\approx 1$.3. If the visual range is inferior to $6 \mathrm{~km}$, them the exponent $\delta$ can be obtained by:

$$
\delta=0.585 \cdot V^{1 / 3}
$$

The presence of precipitation (rain or fog) increases the scattering coefficient. The transmittance can be related with the rainfall rate $(R)$ in $\mathrm{mm} / \mathrm{hr}$, by: 


$$
\begin{array}{r}
\tau_{\text {rain }}=\exp (-(0.05556+0.00848 \cdot R \\
\left.\left.-3.66 \times 10^{-5} \cdot R^{2}\right) \cdot l\right)
\end{array}
$$

The propagation of a laser beam in dense fog or clouds much difficult and attenuations as high as $\approx 50-150 \mathrm{~dB} / \mathrm{km}$ can be found (Strickland, 1999).

The total attenuation to be considered in (1) is the sum of the several partial attenuation factor (eqs (4), (5) and (8))

The geometrical beam expansion, resulting from the beam divergence, is also responsible for a reduction of the optical power coupled to the receiver. It must be also take into account the optical miss alignment between the emitter and the receiver, for systems without autotracking (Kim, 1998).

\section{B. Turbulence}

The atmospheric turbulence arises when air parcels at different temperatures are mixed by wind and convection. This effect produces fluctuations in the density and therefore in the air refractive index. The parameter that describe the disturbances caused by turbulence is the refractive index structure coefficient, $C_{n}$, which usually varies between $5 \times 10-7 \mathrm{~m}^{-1} / 3$ and 8 $\times 10-9 \mathrm{~m}^{-1} / 3$ for situation of strong and weak turbulence, respectively.

The value of $C_{n}$ can be estimated by (Strohbehn, 1978):

$$
\begin{aligned}
& C_{n}{ }^{2}=\left(\frac{h^{-4 / 3}}{3000^{-4 / 3}}\right) \cdot \frac{\left(\frac{79 \times 10^{-6} \cdot P}{(T+273.15)^{2}}\right)}{5.49 \times 10^{-13}} \\
& \left(\left(2.2 \times 10^{-53} \cdot 3000^{10} \cdot\left(\frac{v \cdot \sin (\theta)}{27}\right)^{2}\right) \cdot e^{-3}+10^{-16} \cdot e^{-2}\right)
\end{aligned}
$$

where $h$ is the height in meters, $P$ the air pressure is milibars, $v$ is the wind speed in $\mathrm{m} / \mathrm{s}$ and $\theta$ the angle between the beam and the wind.

The dominant turbulence scale size leads to different effects: (i) if the scale of the turbulence cells is larger than the beam diameter then the dominant effect is the beam wander, that is the rapid displacement of the beam spot, (ii) if the scale of the turbulence cells is smaller than the beam diameter then the dominant effect is the beam intensity fluctuation or scintillation.

The radial variance of beam wander can be described by (Zhu, 2002):

$$
\sigma_{r}^{2}=1.90 \cdot C_{n}^{2} \cdot(2 \cdot w)^{-1 / 3} \cdot l^{3}
$$

where $\mathrm{w}$ is the spot size at the transmitter.

The scintillation is described by a log-intensity distribution (Clifford, 1981), with a variance given by [Wichel, 1990]:

$$
\sigma_{i}^{2}=1.23 \cdot C_{n}^{2} \cdot\left(\frac{2 \pi}{\lambda}\right)^{7 / 6} \cdot l^{11 / 6}
$$


The effect of scintillation can be smoothed by spatial averaging using a width detector area, multiple apertures detector or a spatial diversity with several receivers or emitters (Kim, 1997).

The presence of atmospheric turbulence is also responsible for the beam spreading, contributing to the beam divergence, which is given by [Wichel, 1990]:

$$
a_{t}=2.01 \cdot \lambda^{-1 / 5} \cdot C_{n}^{6 / 5} \cdot l^{8 / 6}
$$

\section{Thermal Blooming}

The molecular absorption by the air of the beam energy, will lead to a temperature gradient in the medium that induces density and index refraction changes. In the presence of air flow (wind) results in a density wavefront destruction which leads in a beam bender directed to the air flow.

The displacement of the beam at the receiver is (Strohbehn, 1978):

$$
u=-\frac{5 \cdot(\gamma-1) \cdot(n-1) \cdot l \cdot\left(\frac{\left\langle I_{0}\right\rangle}{w}\right)^{2}}{6 \cdot \gamma \cdot P \cdot 100 \cdot|v \cdot \sin (\theta)|}
$$

where $\gamma$ is the ratio of specific heats (with a value of 1.4 in air), $\mathrm{n}$ is the refractive index of the air and $I_{0}$ is the beam optical power at the transmitter.

III. Simulation

In this subsection, and for sake of understanding of the modeling described above, a set of simulations is presented based on the atmospheric model described in the previous section. This model was implemented through Matlab in a commercial available photonic simulator, VPI from Virtual Photonics ${ }^{\mathrm{TM}}$.

The free space optical communications system used as reference for these simulations had the following parameters. The propagation distance was $1000 \mathrm{~m}$, oriented in a $158^{\circ}$ heading. The optical power of the beam at the emitter was $40 \mathrm{~mW}$ and at a $780 \mathrm{~nm}$ wavelength, with a radius of $10 \mathrm{~cm}$ and a divergence of 1 mrad. The optical beam is modulated at $2.048 \mathrm{Mb} / \mathrm{s}$ (E1) with an optical extinction ratio of $15 \mathrm{~dB}$. The use of this low bitrate allows us to later compare these results with some experimental ones (Almeida, 2001). For the receiver we have considered a photodiode based O-E converter with a 0.85 responsivity and a 1.4 $\mathrm{Mbit} / \mathrm{s}$ bandwidth pulse reformatting electrical filter, preceded by a $6 \mathrm{~dB}$ attenuator to account the miss alignment losses.

We obtained, for several values of temperature and relative humidity, the attenuation of for $1 \mathrm{~km}$ path link. These results can be observed in figure 3 . 


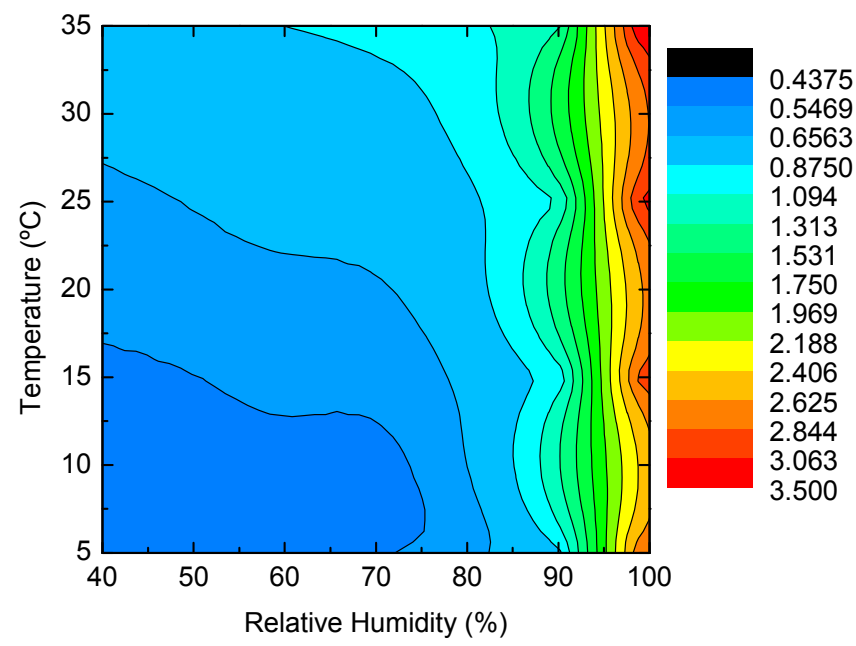

Fig. 3. Optical attenuation for one $\mathrm{km}$ path link as a function of the temperature and relative humidity.

It is clear, from figure 3 that the effect of temperature and humidity in the losses, due to absorption and scattering is important. The total attenuation vary from $\approx 0.5 \mathrm{~dB} / \mathrm{km}$ to 3.5 $\mathrm{dB} / \mathrm{km}$.

The effect of rain fall can also be analyzed with this model. Keeping the values of temperature and relative humidity constant, $25{ }^{\circ} \mathrm{C}$ and $80 \%$ respectively, the attenuation was obtained as function of the rain fall rate, as displayed in figure 4 .

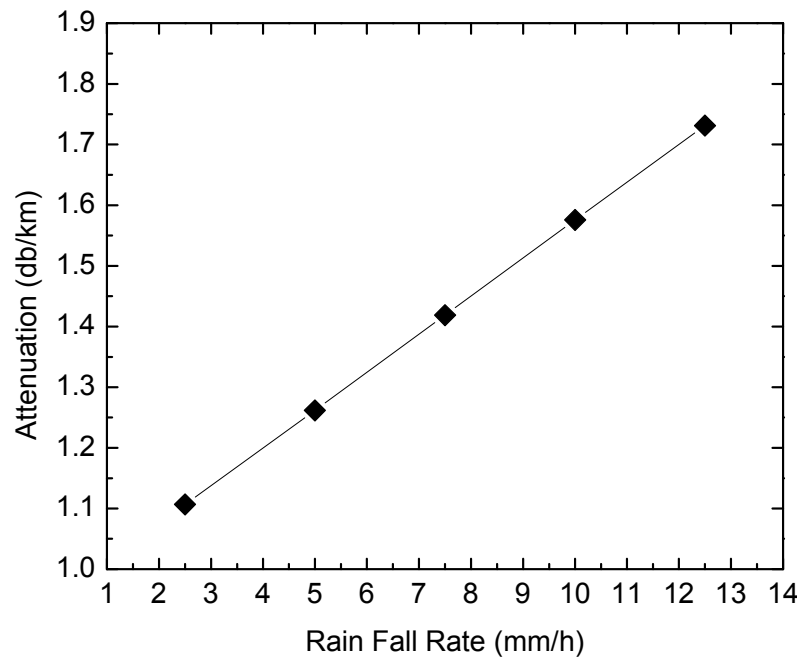

Fig. 4. Optical attenuation for $1 \mathrm{~km}$ path link due to rain. The line is a visual guide. 
The introduction of turbulence in the atmosphere model will result in the observation of scintillation on the received power. In figure 5 is shown the BER (bit error rate) of the received data for $1 \mathrm{~km}$ path direct optical link as function of the received optical power and for several values of the refractive index structure coefficient.

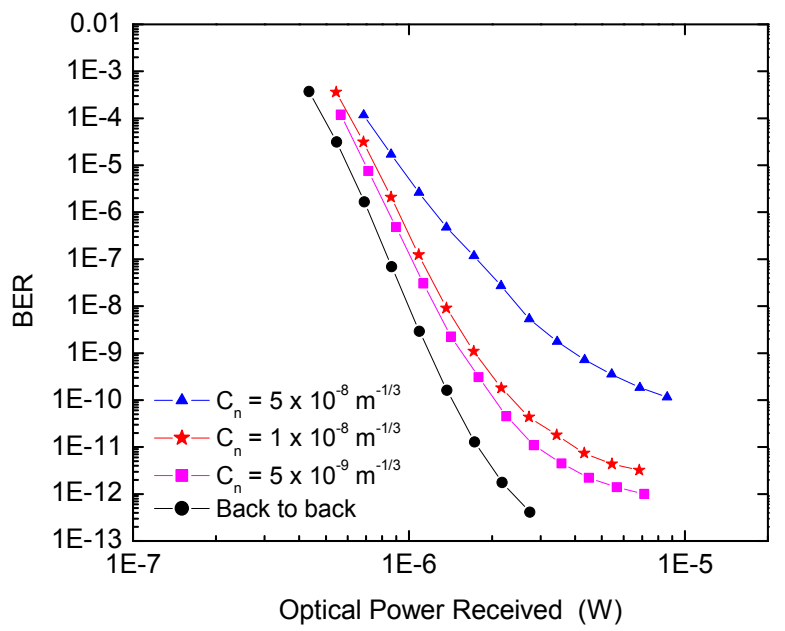

Fig. 5. BER versus the received optical power for several values of $\mathrm{Cn}$. The lines are visual guides.

From the previous figure it is clear that the power penalty depends on the value of $C n$, as it can be observed in the eye diagrams of figure 6 , obtained for a received power of $-22 \mathrm{dBm}$ and for several values of $C_{n}$. The eye diagram of figure 6 a) corresponds to a high turbulent medium with a $C_{n}$ value of $\left.1 \times 10-7 \mathrm{~m}-1 / 3,6 \mathrm{~b}\right)$ is a situation of medium turbulence with $C_{n}$ of $5 \times 10-8 \mathrm{~m}-1 / 3$, while $6 \mathrm{c}$ ) is obtained in a low turbulence medium with a value of $1 \times 10-9$ $\mathrm{m}-1 / 3$ for $C_{n}$.

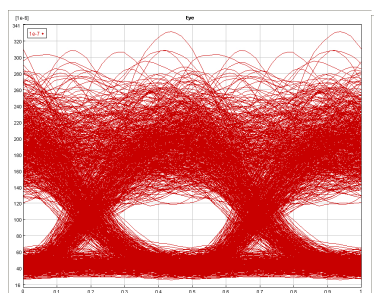

a)

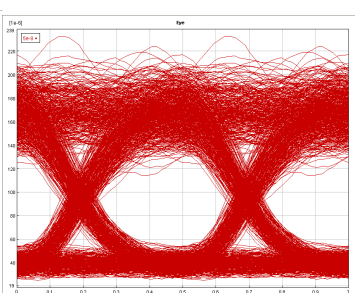

b)

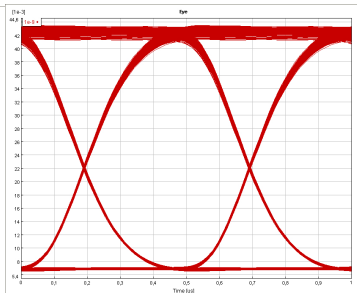

c)

Fig. 6. Eye diagrams obtained for several values of the refractive index structure coefficient: a) $1 \times 10-7 \mathrm{~m}-1 / 3$, b) $5 \times 10-8 \mathrm{~m}-1 / 3$, c) $1 \times 10-9 \mathrm{~m}-1 / 3$.

A reasonable good approach to estimate the BER of a FSO system is to consider only the attenuation (discarding the scattering and thermal blooming but considering the beam wander), then the BER can be written as: 


$$
B E R=\frac{1}{2} \operatorname{erfc}\left(\frac{R P_{R}}{2 \sqrt{2 \sigma^{2}}}\right)
$$

Where $R$ is the detector responsivity, $P_{R}$ the optical power at the detector and $\sigma$ the receiver thermal noise. The impact of the $C_{n}$ factor in the BER can be observed in the figure 7 , where experimental $C_{n}$ factor measured in Rio de Janeiro along the day in February 2003. For the receiver it was considered a typical configuration with $R=0.9 \mathrm{~A} / \mathrm{W}$ and a receiver diameter of $13 \mathrm{~cm}$, the optical power at the emitter is $10 \mathrm{~mW}$ for a link length of $1 \mathrm{~km}$.

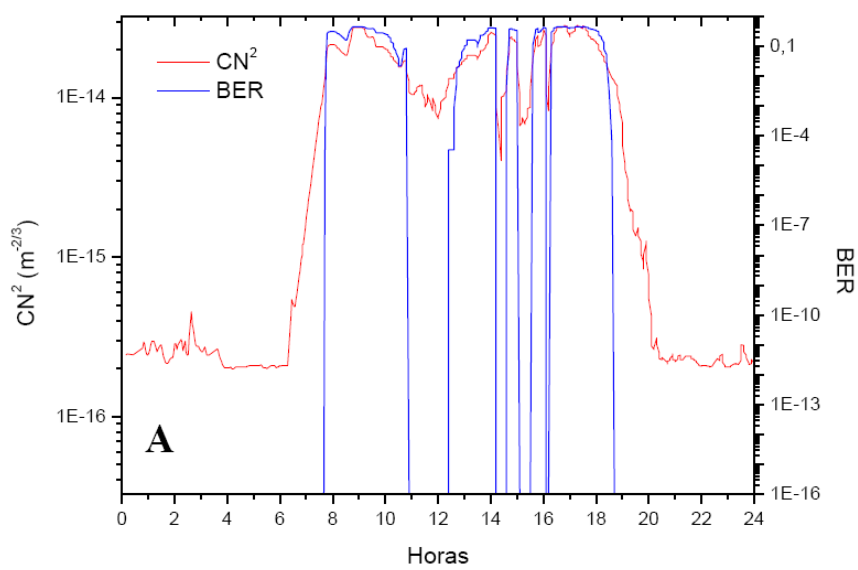

Fig. 7. $C_{n}$ influence in the BER for $1 \mathrm{~km}$ link.

\section{Hybrid network infrastructures: FSO \& RF (B. Geiger - E. Leitgeb - F. Nadeem)}

\subsection{Introduction}

Relying on an unobstructed line-of-sight, FSO links are strongly influenced by atmospheric conditions reducing or influencing visibility, such as fog, precipitation, haze, and scintillation. Fog, as one can expect, is the most critical effect affecting attenuation and, subsequently, availability of the FSO link. Attenuation is caused by scattering, resulting from the fact that the size of the fog particles is in the order of the wavelength of optical and near-infrared waves (as they are used for FSO). Consequently, link distances in coastal or metropolitan environments which are prone to fog are limited to a few hundred meters.

Radio Frequency (RF) links on the other hand show almost negligible fog attenuation if the carrier frequency is chosen accordingly, while they usually suffer from other precipitation types like rain and wet snow. Combining these two technologies to an FSO/RF hybrid network may increase overall availability significantly, guaranteeing quality-of-service and broadband connectivity regardless of atmospheric conditions.

Several types of hybrid system concepts have been introduced in the literature (L. Stotts et alt, 2009; S. Bloom and W. S. Hartley; H. Izadpanah et alt, 2003; T. Elbatt et alt, 2001; F. Nadeem et alt, 2009; E. Leitgeb et alt, 2004; J. Pacheco de Carvalho et alt, 2008; S. Vangala 
et alt, 2007; A. Akbulut et alt, 2005; S. Gurumani et alt, 2008; J. Derenick et alt, 2005; T. Kamalakis et alt, 2005; W. Kogler et alt, 2003; F. Nadeem et alt, 2009; S.D. Milner et alt, 2004; O.I. Kim and E. Korevaar, 2001; H. Wu et alt, 2004; S. Vangala and H. Pishro-Nik, 2007), focusing on increasing availability, bandwidth efficiency, or minimizing system complexity. Resulting from these focuses, hybrid systems can be categorized in three different groups: Redundant, load-balancing, and switch-over hybrids.

\subsection{Description of the RF Communication Links}

As already mentioned, FSO links are strongly influenced by fog attenuation and consequently suffer from long periods of total link loss (E. Leitgeb, 2005). On the other hand, FSO systems provide very high data rates without the requirement of licensing. As a consequence, the RF link for a hybrid FSO/RF system has to be chosen according to the following requirements:

- The RF link should be available whenever the FSO link is not, i.e. it should not be influenced by fog or other weather effects reducing visibility.

- The RF link should provide a similar bandwidth as the FSO link, so that the hybrid system does not suffer from performance degradation.

- The RF link should be operated in a frequency band which does not require licensing, so that this advantage of FSO systems is not lost in a hybrid setup.

Unfortunately, some of these requirements are contradictory. High data rates, or equivalently, bandwidths require high carrier frequencies, which on the other hand either show strong attenuation due to fog or would result in a prohibitively high system complexity. Moreover, these systems operate in license-free, but regulated bands and are thus subject to stringent transmission power restrictions limiting the possible link margin considerably. A higher geometrical loss further adds to the availability issues. Especially during times when rain and fog occur simultaneously, as it often happens in continental climate, both links are suffering from weather effects (E. Leitgeb et alt, 2004; E. Leitgeb et alt, 2005). Scintillations have little or no effect on RF links, since they are not susceptible to changes in the refractive index rather than changes in humidity (S.S. Muhammad, 2005). A more complete discussion of weather effects on RF links is available in ( $\mathrm{H}$. Wu et alt, 2004; ITU-R, 2005). Commercially available bands with very high available bandwidths are centered around $60 \mathrm{GHz}$ and $70 / 80 \mathrm{GHz}$, respectively. While the former, license-free band cannot be exploited for long link distances due to an oxygen absorption peak $(15 \mathrm{~dB} / \mathrm{km})$, the latter provides an interesting field of research for hybrid systems. Peak attenuation due to moderate rain are usually well below $5 \mathrm{~dB} / \mathrm{km}$, whereas fog attenuation is as small as 0.4 $\mathrm{dB} / \mathrm{km}$ for a fog density of $0.1 \mathrm{~g} / \mathrm{m} 3$ - under these conditions a FSO system would suffer from $225 \mathrm{~dB} / \mathrm{km}$ (S. Bloom, 2005). Currently available equipment operating in the 70/80 $\mathrm{GHz}$ band can provide carrier class availability disregarding weather conditions over a distance of 2-3 km achieving 1 Gbps. Unfortunately, this band can only be used after obtaining a low-cost license. Spectra currently unregulated by the ITU lying at $275 \mathrm{GHz}$ are unreachable with current technologies (J. Wells, 2009).

Lower frequency bands (e.g. the license-free ISM bands at 2.4 and $5 \mathrm{GHz}$ ), on the other hand, provide much less bandwidth to the user, leading to a greatly decreased bandwidth performance of the overall hybrid system. However, these systems are not susceptible to fog 
at all (ITU-R, 2005) and also show much smaller influence of rain and snow than systems operating with carrier frequencies beyond $20 \mathrm{GHz}(\mathrm{H}$. Wu et alt, 2004). Multi-user interference, as it is common in license-free bands at lower frequencies, which are accessible by low-cost technologies, can be mitigated by using directional links.

These bands, which also host users of IEEE $802.11 \mathrm{a} / \mathrm{b} / \mathrm{g} / \mathrm{n}$ compliant equipment, are of particular interest since they allow building a hybrid FSO/RF system with commercially available equipment for the RF part as well. Especially the IEEE 802.11a standard is interesting for FSO/RF hybrids, since it is operating in the less populated $5 \mathrm{GHz}$ band and allows a higher transmit power of up to $30 \mathrm{dBm}$ EIRP. Although the standard claims possible data rates of up to $54 \mathrm{Mbps}$, usual limits for long-range directional links are around 20 Mbps. Moreover, the use of this technology offers the possibility of an upgrade to IEEE $802.11 \mathrm{n}$ compliant equipment, claiming data rates of up to $600 \mathrm{Mbps}$ with MIMO functionality. Future studies will show if this technology can also be used for long-rage directional links and thus build the RF component of the proposed hybrid systems.

\subsection{Overview of Hybrid Systems introduced in the literature}

Hybrid systems can be classified into three categories:

- Redundant systems: These systems duplicate data and transmit it simultaneously over both the RF and the FSO link. As a consequence, the data rate of both links has to be equal, resulting in either a requirement for very high frequencies on the RF link or a relatively high FSO underutilization. Moreover, systems which duplicate and recombine data are necessary. Redundant systems provide a high reliability, but suffer from the fact that both links have to be active all the time, wasting a significant amount of energy.

- Switch-Over systems: These systems transmit data only over one link, which is chosen according to link availability. Usually, since the FSO link allows higher data rates, it is chosen as a primary link whereas the RF link acts a backup. Consequently, data rates of both links need not be identical, if one accepts a reduced bandwidth during fog events. Switch-over systems require multiplexers on both ends, algorithms choosing the active link, synchronization, and accurate, timely measurement data of the optical signal strength. However, these algorithms save energy by transmitting over one link only, and can be connected to standard network equipment without protocol overhead (F. Nadeem et alt, 2009).

- Load-Balancing systems: These most sophisticated algorithms distribute traffic among the links according to the quality of their connectivity, thus exploiting the full available bandwidth each time. Besides a measurement of the link quality, these systems require recombination systems on either sides of the hybrid link, often resulting in either significant protocol overhead (F. Nadeem et alt, 2009) or highcomplexity codes which automatically distribute data among different links.

In the literature a wide field of hybrid systems can be found: AirFiber (S. Bloom, 2009), a USbased company pioneered redundant transmission over FSO and RF links, the latter one being a millimeter wave (MMW) link with a carrier frequency at $60 \mathrm{GHz}$. Data rates of approx. $100 \mathrm{Mbps}$ were achieved, but availability was well below the expectations. Wu et alt. (H. Wu et alt, 2004) analyzed FSO and RF link separately and concluded that by using a hybrid network link margin can be reduced significantly to achieve carrier class availability. 
The FSO link was using a $1550 \mathrm{~nm}$ laser source, the RF link was operated in the $60 \mathrm{GHz}$ MMW band. Link distance was $1500 \mathrm{~m}$.
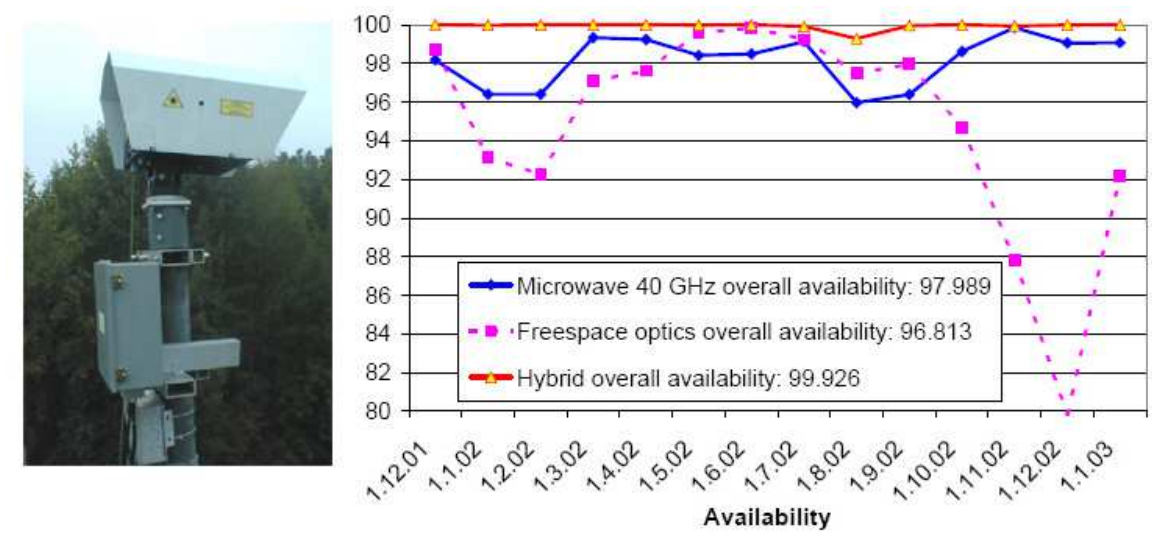

Fig. 8. Redundant hybrid system and availability measurements (with the permission of E. Leitgeb et alt, 2004)

Kim and Korevar (I.I. Kim and E. Korevaar, 2001) studied the distance limitation of FSO systems for both carrier and enterprise applications and showed that carrier class availability can be achieved for much longer link distances if the FSO link is combined with an RF back-up transmitting data redundantly. Leitgeb et alt. performed an experiment in Graz, Austria, over 15 months during 2002-2003, where data was sent simultaneously over two FSO/RF links (E. Leitgeb et alt 2004). The RF link was designed with a carrier frequency of $40 \mathrm{GHz}$, the FSO system transmitted using a $850 \mathrm{~nm}$ laser with a data rate of $155 \mathrm{Mbps}$. The availability was measured over this time for each individual link and for the hybrid combination. The redundant transmission achieved an availability of $99.93 \%$ (see Fig. 8.) Hashmi et alt. (S. Hashmi and H. Mouftah, 2004) also proposed a redundant hybrid system, calculating it based on rain data only for an FSO and a MMW link in the $60 \mathrm{GHz}$ band. They also mentioned that the hybrid system could be used in an asymmetric uplink/downlink scenario where different traffic demands have to be served.

Akbulut et al (A. Akbulut et alt 2005) developed an experimental hybrid FSO/RF switchover system between the two of five campuses of Ankara University, Turkey, located at different locations in the city. The optical link provided a $155 \mathrm{Mbps}$ full duplex connection by using a laser source at $1550 \mathrm{~nm}$ over a distance of $2.9 \mathrm{~km}$. The RF link was compliant to IEEE 802.11b WLAN, operated at $2.4 \mathrm{GHz}$ linking the two terminals at $11 \mathrm{Mbps}$. The switchover algorithm was a power hysteresis. Pacheco de Carvalho et alt. (J. Pacheco de Carvalho, 2008) installed a similar system at the University of Aveiro, Portugal, where a 1 Gbps laser link was backed up by a $75 \mathrm{Mbps}$ (nominal) WiMAX (IEEE 802.16) link. The laser link was operated at $1550 \mathrm{~nm}$, switching was implemented on the network layer via switching between static routes. Power hysteresis was employed, and the link distance was $1.14 \mathrm{~km}$.

Milner and Davis (S.D.Milner and C.C. Davis, 2004) proposed a switch-over system for tactical operations in a general manner, considering protocols for switching between links as well as for traffic re-distribution after a change in the network topology. Their intention was to use two $1550 \mathrm{~nm}$ FSO systems in combination with an RF link operated in the Ku-band 
(12-18 GHz). Kamalakis et alt. (T. Kamalakis et alt, 2005) installed a hybrid switch-over system at the University of Athens, Greece, using a 1 Gbps FSO link and a 100 Mbps MMW link operated at $95 \mathrm{GHz}$ over a distance of $800 \mathrm{~m}$. Also, (L. Stotts et alt, 2009) report about switch-over systems.

Dynamic load balancing is also proposed in literature: ElBatt and Izadpanah ( H. Izadpanah et alt, 2003; T. ElBatt and H. Izadpanah, 2001) proposed a load balancing system distributing traffic among one FSO and several RF links. In this work, however, it is assumed that the amount of traffic on the FSO link affects it availability. Vangala and Pishro-Nik (S. Vangala and H. Pishro-Nik, 2007; S. Vangala and H. Pishro-Nik, 2007) use special non-uniform lowdensity parity check codes to distribute traffic among different links, showing increased link utilization and availability, while BER could be reduced significantly. Finally, Nadeem et alt (F. Nadeem et alt, 2009; F. Nadeem et alt, 2009) analyzed both switch-over and loadbalancing systems based on standard Ethernet equipment with minimum hardware extension. A $155 \mathrm{Mbps}$ FSO system with a $850 \mathrm{~nm}$ laser was used in combination with an IEEE 802.11a link. It was shown that availability almost achieves carrier class values of $99.999 \%$.

\subsection{Hybrid FSO/RF switch-over system}

Switch-over (SO) systems, as they were introduced in Section IV can be illustrated by Fig. 9: Depending on the strength and availability of the links, only one of them is used for transmission. While the FSO link is the primary link, the RF link acts as a back-up. In this section the interested reader will find an overview of the problems in designing such an SO system together with some possible solutions. In particular, synchronization between the switches/multiplexers on both sides, $\mathrm{SO}$ algorithms and possible applications will be analyzed.

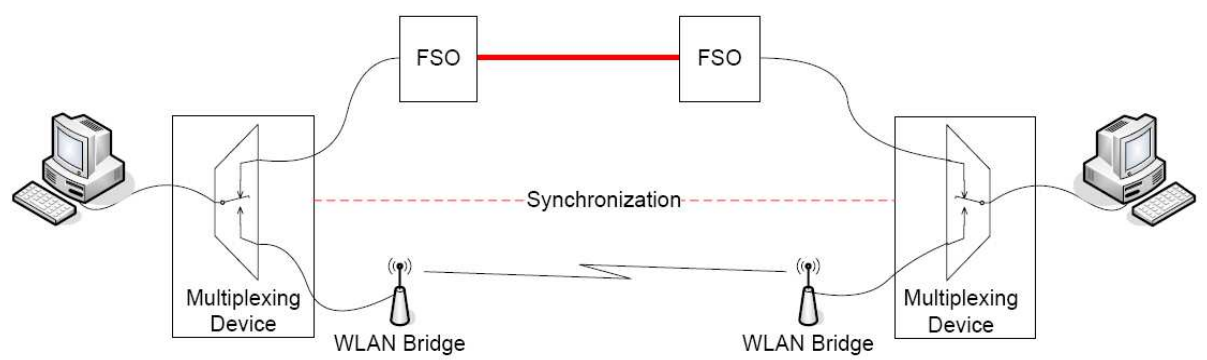

Fig. 9. Application setup of FSO-WLAN switch-over system (with the permission of (F. Nadeem et alt, 2009)

For the simulations, a commercial WLAN link with a carrier frequency in the $5 \mathrm{GHz}$ ISM band will be considered. The WLAN link was built with two embedded PCs using high-gain grid antennas and miniPCI WLAN cards with fairly high receiver sensitivity (depending on the antennas, distances of over $50 \mathrm{~km}$ can be covered). The FSO system is a GoC MultiLink $155 / 2$ system. It supports data rates of $155 \mathrm{Mbps}$ over distances up to $2 \mathrm{~km}$ and uses 4 transmitters at $850 \mathrm{~nm}$. The properties of the FSO and the WLAN system are given in Table 2. It is further assumed that the transceivers of both links are able to provide status information. 


\begin{tabular}{|l|l|l|}
\hline Spec. & FSO & WLAN \\
\hline \hline TX wavelength/frequency & $850 \mathrm{~nm}$ & $5.20-5.825 \mathrm{GHz}$ \\
TX technology & VCSEL & Semiconductor amplifier \\
TX power & $2 \mathrm{~mW}(+3 \mathrm{dBm})$ & $1.26 \mathrm{~mW}(1 \mathrm{dBm})$ \\
TX aperture diameter & $4 \times 25 \mathrm{~mm}$ lens & $30 \mathrm{dBi}$ \\
Beam divergence & $2.5 \mathrm{mrad}$ & \\
RX technology & Si-APD & Semiconductor amplifier \\
RX acceptance angle & $2 \mathrm{mrad}$ & $30 \mathrm{dBi}$ \\
RX aperture & $4 \times 80 \mathrm{~mm}$ lens & $-94 \mathrm{dBm}$ \\
RX sensitivity & $-41 \mathrm{dBm}$ & $14 \mathrm{~dB} / \mathrm{km}$ \\
Spec. Margin & $7 \mathrm{~dB} / \mathrm{km}$ & \\
\hline
\end{tabular}

Table 2. Properties of FSO and WLAN Systems (with the permission of F. Nadeem et alt, 2009)

Since FSO is the primary link switching is exclusively determined by the ORSS: As soon as the ORSS indicates a total link loss for FSO, an SO operation to the WLAN link is performed. Similarly, as soon as the optical system restores connectivity, data packets are transmitted over this link only.

Switching and Synchronization: Switching itself can be done on almost all layers of the OSI reference model, although it is done preferably on the lower layers 1-3. Hardware multiplexers, virtual LAN switches or commercially available Ethernet routers are only a few possible switches to name. Switching on the physical layer (PHY) has the advantage of fast reconfigurations of the links, at least if the connected wireless systems are capable of such quick changes. If both links are providing Ethernet compliant interfaces only, fast physical layer switching may be problematic; connecting a CAT5 cable to an Ethernet device always requires a so-called auto-negotiation phase where the devices determine link speed, duplex mode and other transmission parameters. This negotiation takes some time, usually in the order of 1-2 seconds. Consequently, during this time data cannot be transmitted, resulting in a relatively long link loss time (LLT). As it was shown in (F. Nadeem et alt, 2009) LLT is around $1.62 \mathrm{~s}$ for a self-made hardware multiplexer.

Moreover, it may occur that packets are cut in halves and lost during the switch-over process. On the other hand, switching on the physical layer has the advantage of a completely transparent link between the two networks to be connected via the hybrid system. Switching on the medium access (MAC) layer also provides a transparent link, if the wireless connections allow it. FSO equipment usually operates on the PHY layer and thus is protocol independent. WLAN equipment can at least be configured in a way that it is transparent to the MAC layer (bridging or WDS bridging modes), so that source and destination MAC addresses are unchanged over the link. Switching on MAC layer, e.g. by reconfiguring a virtual LAN (VLAN), has the advantage that no physical re-connections and subsequent auto-negotiation phases are necessary, significantly reducing LLT. (F. Nadeem et alt, 2009) reports LLTs of 1.29 $\mathrm{s}$ for a commercially available VLAN device. In some cases, however, the VLAN device requires a soft re-boot after configuration, slightly prolonging the LLT (F. Nadeem et alt, 2009). However, more sophisticated devices use a store and forward algorithm which at least guarantees that every packet arriving at the multiplexer is forwarded - if not over the active link. Switching on network layer can be done via routers and can rely on both physical measurements of the ORSS or interface statistics of the router ports, such as BER and packet 
loss (J. Pacheco de Carvalho et alt, 2008). In the former case the router needs special hardware extensions or interfaces to some measurement equipment, in the latter the router has to be capable of running a custom-made program. Furthermore, switching based on physical signal strengths has the advantage that it does not rely on actual errors, but allows for implementation of a more or less generous link margin. Switching itself is usually done by changing the route metrics (J. Pacheco de Carvalho et alt, 2008) of the different links according to the measurements. Consequently, all packets are transmitted, although not all may reach its destination. Moreover, one can expect that depending on the type of link status information available reactions on changes in the ORSS are delayed. Links switched on the network layer are usually not transparent to lower layers. In order to provide full connectivity, synchronization between the different multiplexers has to be ensured. Assuming that the channel is reciprocal one may state that both sides of the system will always measure the same ORSS and therefore chose the same link as active automatically. However, usually one does not want to base a hybrid system designed to achieve maximum reliability on that assumption. Moreover, using a side channel for transmitting information about which link to take is questionable as well, because that very channel has to be made reliable itself. Of course, one can feed such information into both the FSO and the RF link, but that certainly adds to the complexity of the system. Besides, it was the main intention of the SO system that at each time instant only one link has to be active. Finally, an asymmetric scenario, where one of the multiplexers chooses the link according to the ORSS would be possible. The other multiplexer accepts packets from either link, but responds only over the very link from where the last packet arrived. Such a self-synchronizing setup, as it was introduced in (F. Nadeem, 2009) has the disadvantage that it inherently relies on quasi-continuous transmission from the network on the side of the active multiplexer - a condition which is usually fulfilled by higher-layer protocols, such as TCP. In any case, despite all considerations about synchronization and switching, the overall hybrid network still has to be considered unreliable; the difference, however, is that the availability is increased significantly.

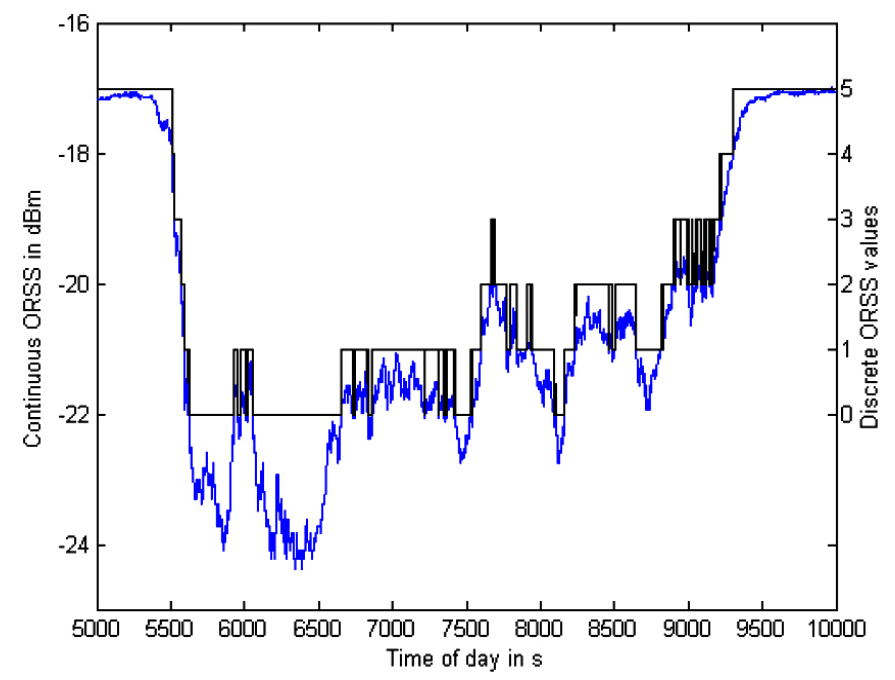

Fig. 10. Comparison of discrete and continuous ORSS values. (with the permission of B. Flecker, 2006) Fog event from October 25th, 2005, 03:00 to 11:00. 
Switch-Over Algorithms: After deciding upon the layer on which switching is performed, upon the data which is determining the active link, and the synchronization method, the designer of the hybrid SO system has to take a multitude of switch-over algorithms into consideration.

Remembering the advantages of physical measurements describing the link status we will put special emphasis on SO systems switching based on those measurements. This, however, rises an important question: Can it be guaranteed that the FSO system (which purely determines the active link) provides link status information in an accurate, timely manner? It can be taken as granted that the system itself measures and uses ORSS information, but is this information accessible to the user over a certain interface? The MultiLink 155/2 system for example indicates the ORSS continuously with a LED bar (discrete amplitude as shown in Fig. 10), but provides this data over an RS232 interface on a per-second basis only (discrete time). Somewhere within the system, however, the time and amplitude continuous ORSS will be available (as also shown in Fig. 10). Thereby one can assume that the previous assumption of link status information provided to the user can be justified, even if hardware reconfiguration are necessary. As one can see in Fig. 10, especially during the gradient from clear sky conditions to foggy weather there are many variations in the ORSS. These variations, as one can expect, cause a certain threshold to be crossed multiple times. If now the SO system is designed to employ a straightforward threshold comparison (TC) algorithm, it would suffer from frequent switching between the links due to these variations. Since after each switching operation a certain time is required to restore the link completely (so called link loss time, or LLT), frequent switching would cause reduced bandwidth and availability. Consequently, other algorithms coping with these variations have to be evaluated - it is the purpose of this section to introduce some of them and compare their performance.

a) Power Hysteresis (PH): A power hysteresis defines two thresholds and two states: a lower and an upper threshold, WLAN and FSO operation. If during FSO operation the lower threshold is crossed, WLAN is activated. If during WLAN operation the upper threshold is crossed, FSO is activated - it's as simple as that to prevent the system from switching back and forth. The width of the hysteresis (i.e. the distance between upper and lower threshold) depends on the amplitude of variations and has to be optimized with respect to actual system measurements. To maximize availability, the lower threshold has to be set to values equal to or greater than the receiver sensitivity of the FSO device. b) Time Hysteresis (TH): Relating variations in the ORSS to bouncing of electrical contacts, one can also use techniques called debouncing to cope with these variations. Such techniques usually employ a wait period $\mathrm{T}$ during which the ORSS are evaluated and during which after every threshold crossing the wait period is restarted. Consequently, only if the signal does not cross the threshold for a certain time, an SO operation is performed. The duration of the wait period in that case is determined by the frequency and the amplitude of the variations. To maximize availability, the wait period can be set to different values for crossing the threshold in either directions; in the limiting case, the wait period can even be omitted for switching from FSO to WLAN. c) Filtering: Treating variations in the ORSS as noise, methods for noise mitigation come into view. Most prominently, low-pass filtering can be named as such a method. Different realizations of low-pass filters in the analog (RCnetwork) and digital (moving average filter, raised-cosine filter, etc.) domain are possibilities to cope with this unwanted noise. Filters are characterized by their order, pass 
and stop band characteristics, and by their cut-off frequency. These characteristics have to be designed with respect to the frequency of the variations. It is of vital importance that the frequency of these variations is in the stop band, while the highest occurring frequency in climatic changes still lies in the pass band to allow for a timely reaction on an emerging fog event.

Moreover, combinations of these methods can be considered (e.g. filtering and hysteresis methods, power hysteresis and debouncing, etc.). Unfortunately, seasonal and diurnal, as well as geographic peculiarities make a general design or general optimization of parameters impossible. The reader will understand that the design of a SO system in a coastal area with dense fog conditions differs from a system in a metropolitan area, where moderate fog can be expected. The following simulations therefore focus on the continental, metropolitan climate of Graz, which is characterized by moderate, persistent fog events during fall and winter and strong rainfall during summer.

Simulations and Results: For the simulation, measurement data was taken from (B. Flecker et alt, 2006). For parameter optimization the particular fog event depicted in Fig. 10 was used. The benefit of focusing on one fog event is based on the fact that the influence of LLT after switching is increased compared to the influence on an all-year average availability. Moreover, as it can be seen in Fig. 1, fog events mainly occur during fall and winter, making a separate analysis of these seasons sensible. Assuming little or no unavailability during the summer months, simulation data can be extrapolated. Receiver sensitivity of the FSO system was set to $-22 \mathrm{dBm}$. For this value, a significant number of threshold crossings occurred which allows an optimization of the algorithms. Using this sensitivity, the fog event under consideration yielded an FSO availability of only $67.43 \%$. Link loss time after switching was set to $3 \mathrm{~s}$ in order to include an additional margin to link re-establishment. For bandwidth simulations, bandwidths of the FSO and WLAN link were set in accordance to (F. Nadeem et alt, 2004) to $91.9 \mathrm{Mbps}$ and 18.8 Mbps, respectively. The WLAN link was assumed to be active whenever FSO was inactive. This assumption holds for fall and winter periods where FSO outages are usually caused by fog only and where rain is rarely occurring simultaneously. During summer months where strong rainfall in combination with severe fog affects both links this assumption may not be valid anymore (E. Leitgeb et alt, 2004).

As one can imagine, finding the best algorithm parameters is related to finding a trade-off between availability and bandwidth efficiency. While WLAN may be available throughout the year, its bandwidth is prohibitively low. Consequently, the simulations are limited by a minimum bandwidth of $60 \mathrm{Mbps}$. A more complete evaluation of simulation results and a comprehensive discussion of this topic can be found in (F. Nadeem et alt, 2009).

a) Threshold Comparison: Pure threshold comparison (TC) is done by comparing the ORSS to the RX sensitivity and switching based on the outcome of this comparison. TC yields an increase in availability to $98.62 \%$ while achieving best bandwidth performance (see Table 3 ). This can be explained by the fact that TC uses the FSO link whenever it is available, and the outstanding bandwidth of this link compensates for relatively high unavailabilities due to LLTs. However, for maximizing availability this may not be the best of all choices as Fig. 11 shows. b) Power Hysteresis: For all simulations, the width of the power hysteresis was set to $1 \mathrm{~dB}$ and the lower threshold was varied. Fig. 12 shows that availability can be increased significantly by increasing the lower threshold to values much greater than the receiver sensitivity. The only problem is that by increasing this threshold FSO underutilization increases and, subsequently, bandwidth efficiency is low. E.g. to obtain a minimum 
bandwidth of $60 \mathrm{Mbps}$, the lower threshold has to be below $-21.7 \mathrm{dBm}$. In these regions, also the beneficial effects of filtering cannot be exploited anymore, because the time to react on changes in the ORSS due to fog increases.
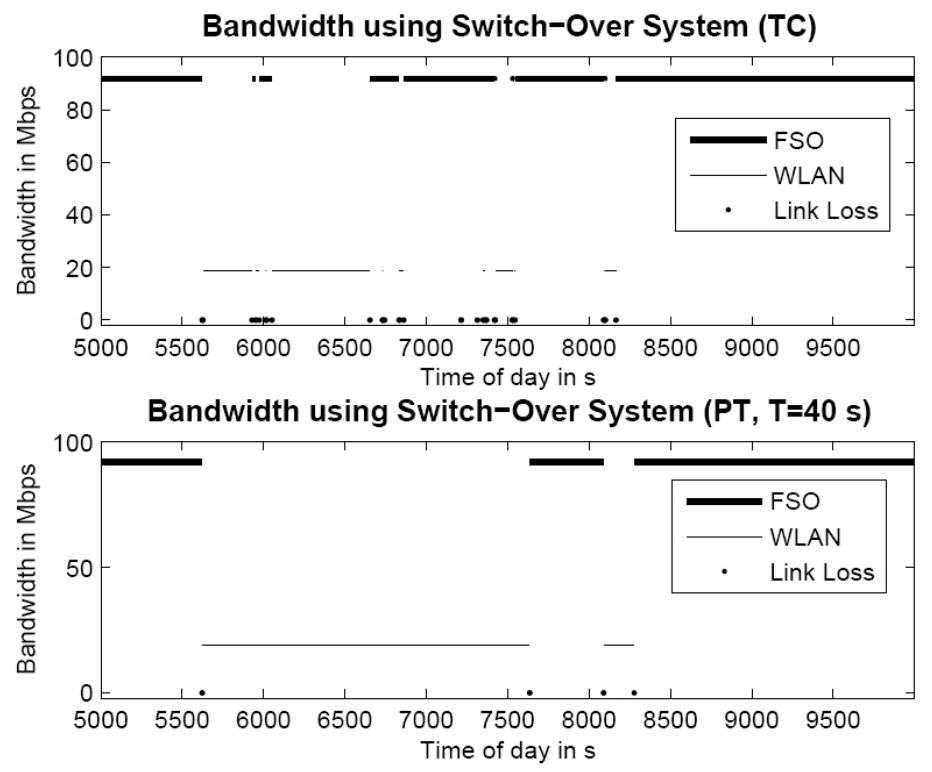

Fig. 11. Bandwidth for different switch-over methods (with the permission of F. Nadeem et alt, IET submitted 2009)

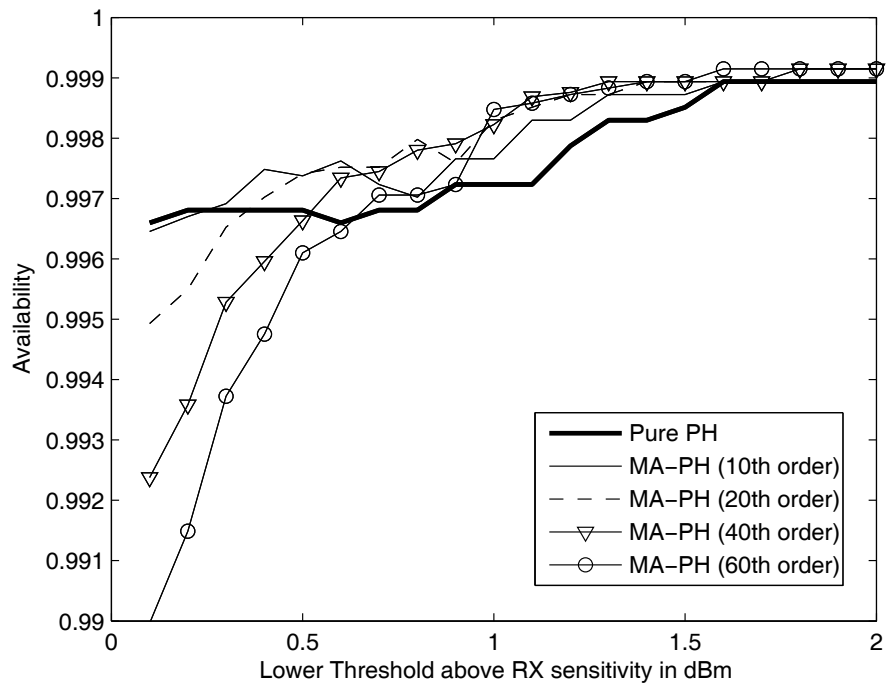

Fig. 12. Availability for pure PH and MA-PH (with the permission of F. Nadeem et alt, 2009) 


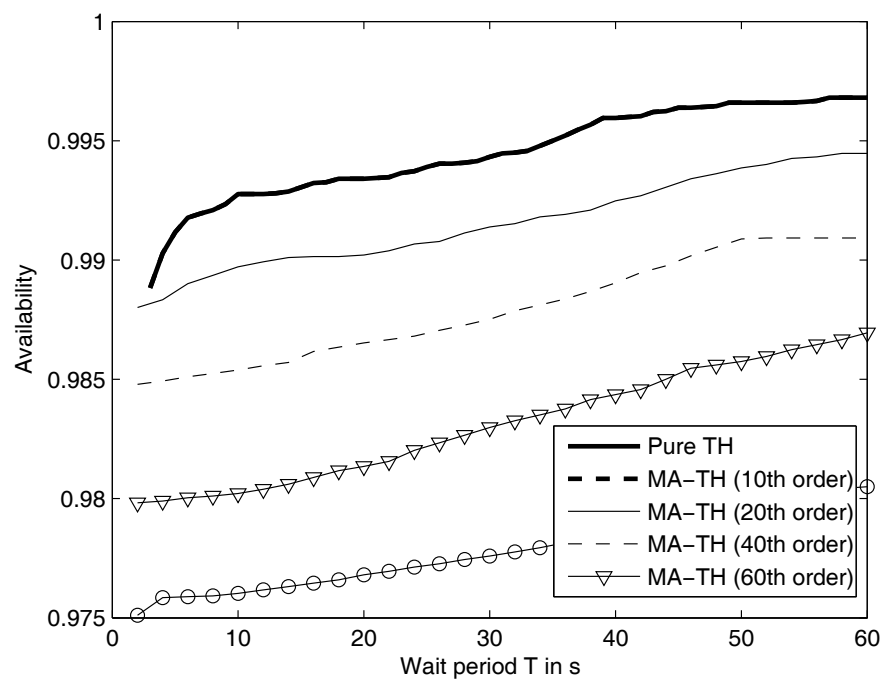

Fig. 13. Availability for pure TH and MA-TH (with the permission of F. Nadeem et alt, 2009)

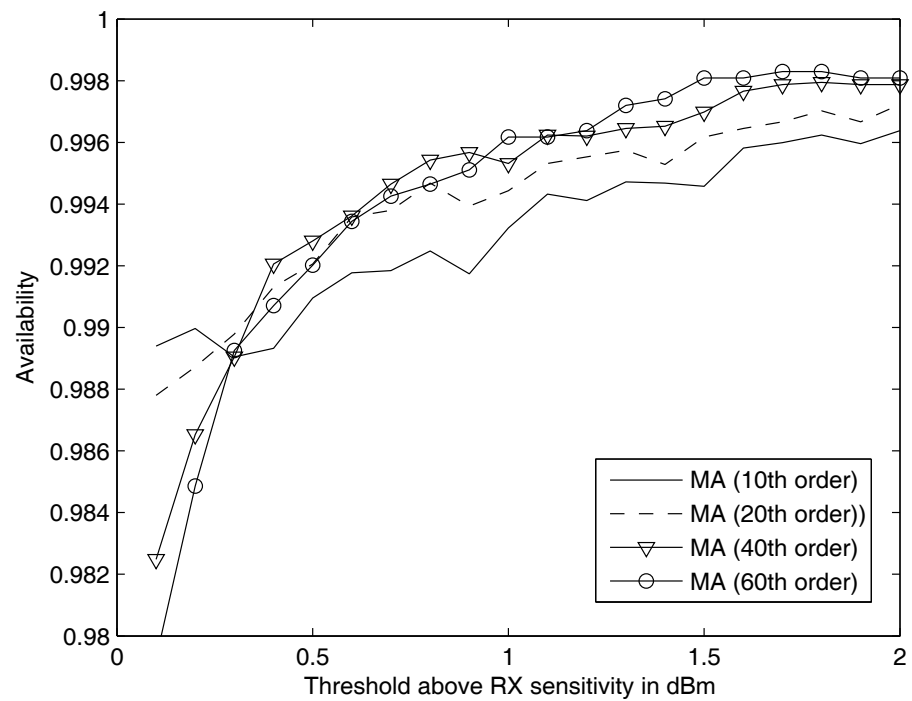

Fig. 14. Availability for different filter orders (with the permission of F. Nadeem et alt, 2009)

c) Time Hysteresis: For the time hysteresis the threshold was set to the receiver sensitivity, and the wait period $\mathrm{T}$ was varied as a simulation parameter. As seen in Fig. 13, availability can be increased significantly. Moreover, FSO underutilization is low, so the minimum bandwidth of $60 \mathrm{Mbps}$ is achieved for all depicted values of T. Filtering beforehand is 
counter-productive. d) Filtering: For filtering, the threshold was increased in steps starting from the receiver sensitivity. As the only filter type, a moving average (MA) filter was considered, where the order $\mathrm{N}$ of the filter automatically determines its cut-off frequency (other filter types are discussed in (F. Nadeem et alt, 2009). Fig. 14 shows that availability increases with increasing thresholds. Interesting, though, might be the fact that higher orders (i.e. lower cut-off frequencies) perform better than lower ones, as long as the threshold is set to values high enough. High-order filters perform smoothing, but do not allow timely reactions on critical changes in the ORSS. Consequently, high availability is only achievable with a combination of smoothing and a large margin to the receiver sensitivity.

This in turn leads to FSO underutilization and limits maximum threshold values to $-21 \mathrm{dBm}$ to obtain a minimum bandwidth of $60 \mathrm{Mbps}$. In these regions, however, lower filter orders outperform higher orders.

e) Combined Power and Time Hysteresis: For the combined power and time hysteresis the lower threshold was set to the receiver sensitivity and the width of the hysteresis was $1 \mathrm{~dB}$. The wait period of the time hysteresis portion was varied. As it can be seen in Fig. 15 and Table 3, pure PT delivers best results in term of availability. Furthermore, minimum bandwidth of $60 \mathrm{Mbps}$ can be achieved for wait periods below $40 \mathrm{~s}$, where availability still has values above $99.8 \%$. Extending this simulation to the whole measurement campaign, availabilities of $99.988 \%$ can be achieved, as it is shown in Table 3. Simulations proved that by doubling this period to $\mathrm{T}=80 \mathrm{~s}$, availability could be increased to $99.997 \%$. Taking these values into consideration one can see that carrier class availability becomes a graspable goal, even for hybrid switch-over systems.

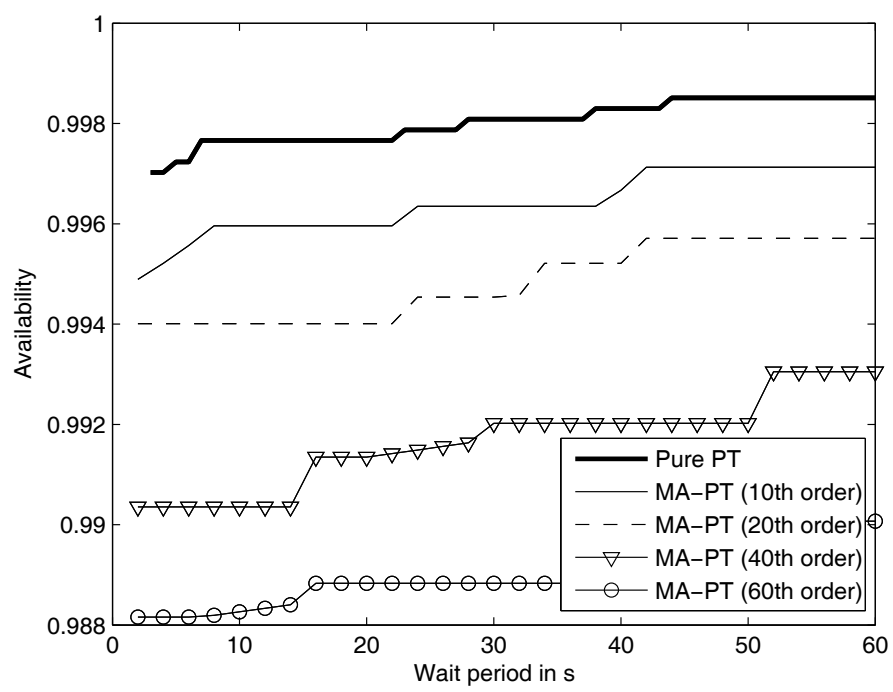

Fig. 15. Availability for pure PT and MA-PT (with the permission of F. Nadeem et alt, 2009) 


\begin{tabular}{|lc|c|c|c|}
\hline & & Pure FSO & TC & PT (T=40 s) \\
\hline \multicolumn{5}{|c|}{ Results for fog event } \\
\hline Availability & $\%$ & 67.43 & 98.62 & 99.83 \\
Link Loss & $\%$ & 38.62 & 1.38 & 0.17 \\
Bandwidth (HDX) & Mbps & 61.96 & 67.30 & 60.97 \\
FSO underutilization $\%$ & 0 & $\approx 0$ & 9.61 \\
\hline \multicolumn{5}{|c|}{ Results for overall campaign } \\
\hline Availability & $\%$ & 90.71 & 99.76 & 99.97 \\
Link Loss & $\%$ & 9.29 & 0.24 & 0.03 \\
Bandwidth (HDX) & Mbps & 83.36 & 84.97 & 83.74 \\
FSO underutilization & $\%$ & 0 & $\approx 0$ & 1.35 \\
\hline \multicolumn{5}{|c|}{ Results for whole year (extrapolated) } \\
\hline Availability $\%$ & 96.13 & 99.90 & 99.988 \\
Link Loss (HDX) & $\%$ & 3.87 & 0.10 & 0.012 \\
Bandwidth (Hops & 88.34 & 91.83 & 91.79 \\
FSO underutilization & $\%$ & 0 & $\approx 0$ & 0.56 \\
\hline
\end{tabular}

Table 3. Performance comparison of different switch over methods (with the permission of F. Nadeem et alt IET submitted 2009)

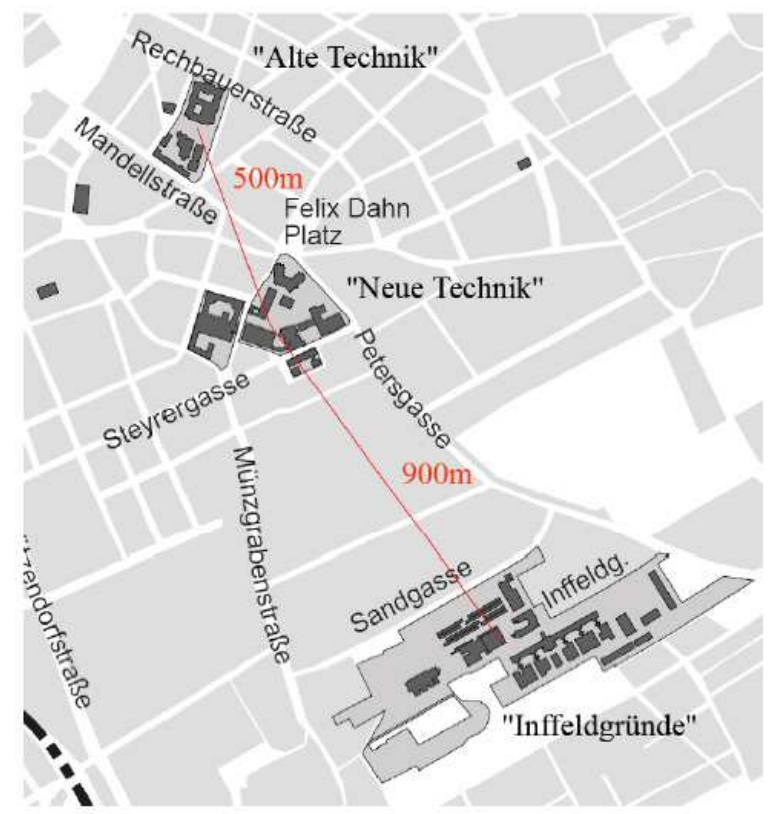

Fig. 16. Map of the campus of the Technical University of Graz

An Application: Interconnection of different sites of the campus Finally, to conclude about hybrid switch-over systems, a possible application scenario shall be introduced, where different sites of the campus of Graz University of Technology will be interconnected. Such an application is widely evaluated in the literature (J. Pacheco de Carvalho et alt, 2008; A. Akbulut et alt, 2005), but only (F. Nadeem et alt, 2009) considers not only availability of the different links but also traffic demands of the different sites. In Fig. 16 one can see the 
location of the main sites of the campus, which are known as "Alte Technik", "Neue Technik" and "Inffeldgründe". The latter one is the largest, housing many offices and student computer rooms. Moreover, one can see that the distance between the sites never exceeds $2 \mathrm{~km}$, making the use of directional WLAN links and FSO links possible. For evaluation purposes, characteristics described in Table 2 were considered. Moreover, it was assumed that the line-of-sight for the FSO and for the WLAN link is free. As already mentioned availability of the FSO link is generally high during the summer months, and during the winter months only during daytime (cf. Fig. 1 and Fig. 2) for the continental climate of Graz. Traffic demands were recorded using the Multi-Router-Traffic-Grapher (MRTG), where green bars indicate incoming and blue lines indicate outgoing traffic.

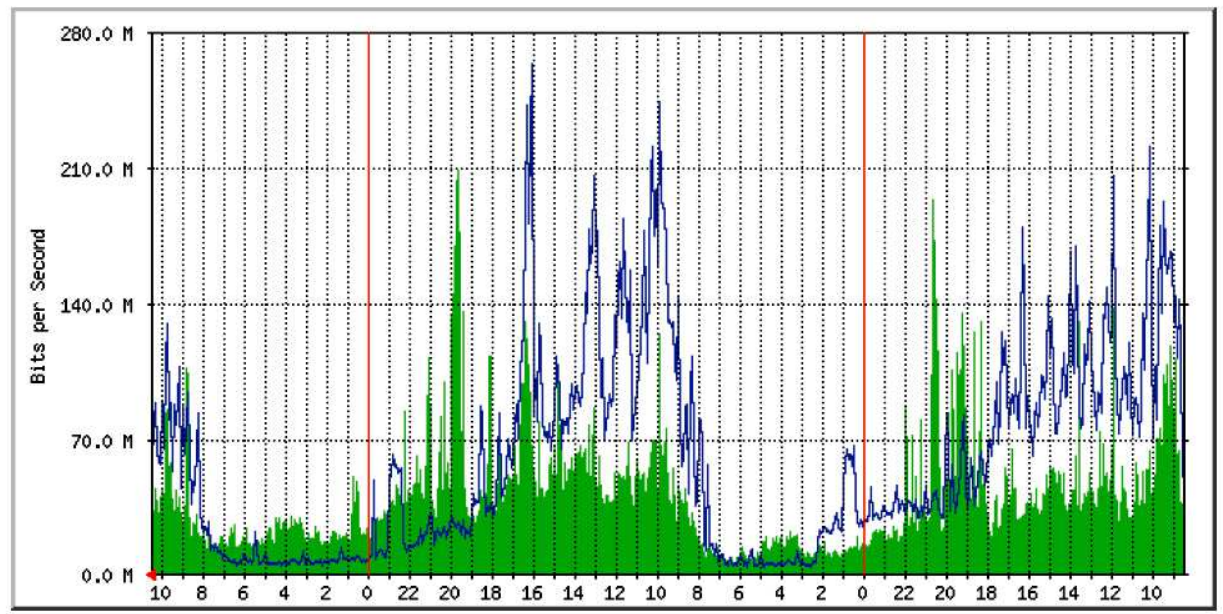

Fig. 17. Traffic data recorded for "Inffeldgasse" (with the permission of F. Nadeem et alt, 2009)

Traffic recordings were made during December 2008, assuming that the average availability due to fog is similar as in Fig. 1. Fig. 17 shows the traffic demands for campus "Inffeldgasse" on December 3rd, 2008. It can be seen that peak traffic demands are occurring between 10 am and $4 \mathrm{pm}$, medium traffic was caused from 8 am to 10 am and from 4 pm to $6 \mathrm{pm}$, whereas traffic during the night time is low. Obviously, the major traffic requirements coincide with office and lecture hours. These considerations do not only hold for a particular day, but throughout the year - naturally, on holidays and weekends, traffic demands are much lower. Moreover, one can see that this peak of incoming traffic at 8 pm occurs every day, which is most likely related to an automatic backup. Scheduling such events more properly, traffic demands can be distributed accordingly. Simulations were performed using a set of measurements of the years 2000 and 2001 (J. Tanczos, 2002). Link bandwidth was set to $155 \mathrm{Mbps}$ for FSO and to $15 \mathrm{Mbps}$ for WLAN, respectively. For the WLAN link a slightly lower bandwidth was taken, assuming that the Fresnel zones may be partially blocked by surrounding buildings and trees. Link loss time was neglected, since it affects the average bandwidth only very little. A more complete discussion of these things can be found in (F. Nadeem et alt, 2009). Comparing Fig. 18 with Fig. 17, the diurnal changes in the traffic requirements are reflected in the average as well. Furthermore, one can see from Fig. 18 that 
the proposed hybrid FSO/WLAN switch-over system can satisfy traffic demands on average. Unfortunately, peak traffic demands of campus "Inffeldgasse" exceed even the available bandwidth for FSO, let alone WLAN. However, by using multiple links of each technology, or newer, more sophisticated equipment (such as Gigabit FSO equipment and IEEE 802.11n standard compliant WLAN links), traffic demands could be satisfied in a highly reliable manner over wireless links.

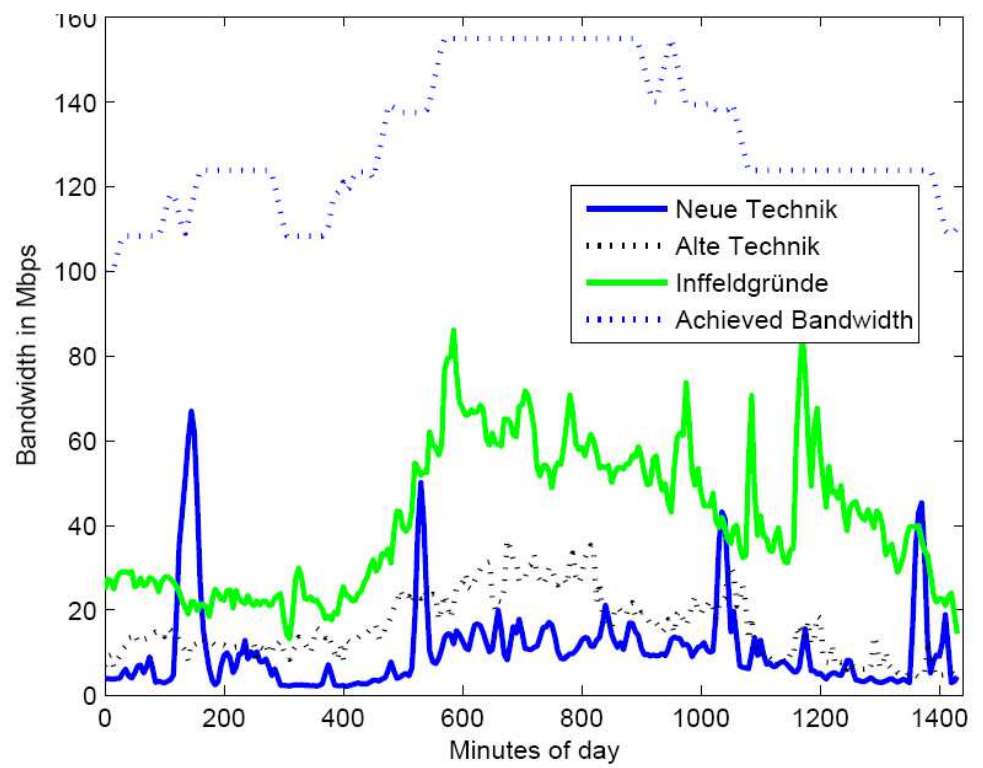

Fig. 18. Average required and achieved bandwidth (with the permission of F. Nadeem et alt, 2009)

\section{Blue sky applications: inter satellite, inter planetary, under sea, chip to chip FSO communications (G. Incerti - G.M. Tosi Beleffi)}

The today increase of the networks complexity, with several devices and subsystems intensively used, involves an aggressive use of the bandwidth management thus to guarantee an high rate and security, especially in military scenarios. In fact, the military applications requires more strictly features respect to the civilian applications. The bandwidth offered by the optical cables is very high and for this reason the optical fibres are also used in military area. Inside airplanes, UAVs, vessels, cars and so on. Several informations and data can run through the same optical fibre and an high rate can be transmitted and managed. We started with this introduction on military purposes because this is the first market that boost the optical wireless, from the paper to the real implementation. FSO communication, infact, is a valid solution especially in military situations because of the previously mentioned ability to guarantee a confidential transmission with a huge bandwidth. 


\begin{tabular}{|c|c|c|}
\hline Challenge & $\begin{array}{l}\text { Mitigation } \\
\text { approach }\end{array}$ & Description \\
\hline $\begin{array}{l}\text { Pointing, } \\
\text { acquisition, and } \\
\text { tracking }\end{array}$ & $\begin{array}{l}\text { RF/FSO hybrids } \\
\text { Adaptive optics }\end{array}$ & $\begin{array}{l}\text {-RF system facilitates coarse acquisition and tracking } \\
\text {-An RF channel can serve as control channel for FSO data } \\
\text { link } \\
\text {-Adaptive optics systems achieve very fine beam steering } \\
\text { and tracking }\end{array}$ \\
\hline $\begin{array}{l}\text { Weather/ } \\
\text { environment }\end{array}$ & $\begin{array}{l}\text { Path redundancy } \\
\text { RF/FSO hybrids }\end{array}$ & $\begin{array}{l}\text {-Path redundancy and topology control are implemented } \\
\text { in an FSO network to counteract link obscuration } \\
\text {-Environmental obscuration for optical may be } \\
\text { permissible for RF or vice versa }\end{array}$ \\
\hline Turbulence & $\begin{array}{l}\text { Adaptive optics } \\
\text { Channel } \\
\text { coding/Diversity }\end{array}$ & $\begin{array}{l}\text {-Adaptive optics correct beam distortion } \\
\text {-Channel coding/diversity improve BER through forward } \\
\text { error correction }\end{array}$ \\
\hline $\begin{array}{l}\text { Eye safety } \\
\text { Eye safety }\end{array}$ & $\begin{array}{l}\text { Infrared wavelengths } \\
\text { Adaptive optics }\end{array}$ & $\begin{array}{l}\text {-Infrared wavelengths such as } 1550 \mathrm{~nm} \text { are more eye safe } \\
\text { than visible wavelengths } \\
\text {-Adaptive optics reduce the need for increased power by } \\
\text { correcting beam for improved SNR }\end{array}$ \\
\hline Networking & $\begin{array}{l}\text { RF/FSO hybrids } \\
\text { QoS techniques }\end{array}$ & $\begin{array}{l}\text {-RF system provides channel for topology control, link } \\
\text { monitoring, and broadcasting network status } \\
\text {-Differentiated services protocols sort data by priority to } \\
\text { counter capacity changes } \\
\text {-Application layer QoS algorithms prioritize data }\end{array}$ \\
\hline
\end{tabular}

Table 4. FSO mitigation approach (Juan C. Juarez et al., 2006)

The limited scenario offered by the radio frequency (RF) spectrum available for military use, contributed to the exploration of alternative systems able to convey the secret informations generated by military devices and/or systems. RF based systems reach only hundreds of Mbps per link and the RF beam cover an high area, in terms of spatial aperture, thus increasing the eavesdropping percentage. On the contrary, FSO systems can guarantee robust optical link with a very small beam size. Granting, at the same time, a huge bandwidth in the order of Gbps. Confining the data flow in a small spatial portion represent an advantage because becomes very difficult to detect the beam and subsequently drop some information from one or more miscreants. Furthermore, several beams, close to each other, can be used at the same time to transport the information without any kind of interference and or interaction.

The precision in the pointing and tracking steps is still a challenge especially in complex and variable scenarios like, for example, the sea one. Mounting FSO on vessels, infact, means, first of all, that a fast tracking system should be implemented. Maintaining, of course, a minimum power budget and the numeric aperture already set. In particular, for the military applications, is required an high degree of accuracy to obtain an alignment of laser beam with the receiver (Juan C. Juarez et al., 2006).

In order to win the challenges induced by the adoption of FSO systems in the communication scenario, sometime is possible to discover the presence of RF backup lines, as supporting elements of the optical counterpart. This is commonly referred as an hybrid communication system. The hybrid system shares a common aperture and the use of FSO with RF system permit to facilitate principal function like for example control signalling, 
tracking, acquisition and signals discovery. The RF beam is used to search the other device (neighbour discovery) or to start the acquisition step. The RF beacon is used also as control signalling and to rehabilitate the communications in case of optical channels fades.

In order to minimize the dependence from a single link, reconfigurable FSO links can be accomplished. Path redundancy and topology control are two ways to set up a fast and smart network able to counteract in case of path obscuration. Moreover, to compensate the environment effects without increase the total beam power, the adoption of adaptive optics such as deformable mirrors, is considered a proper solution. In the following figure, are illustrated several static and mobile nodes. This is a real scenario in which an FSO link can be established in a few time.

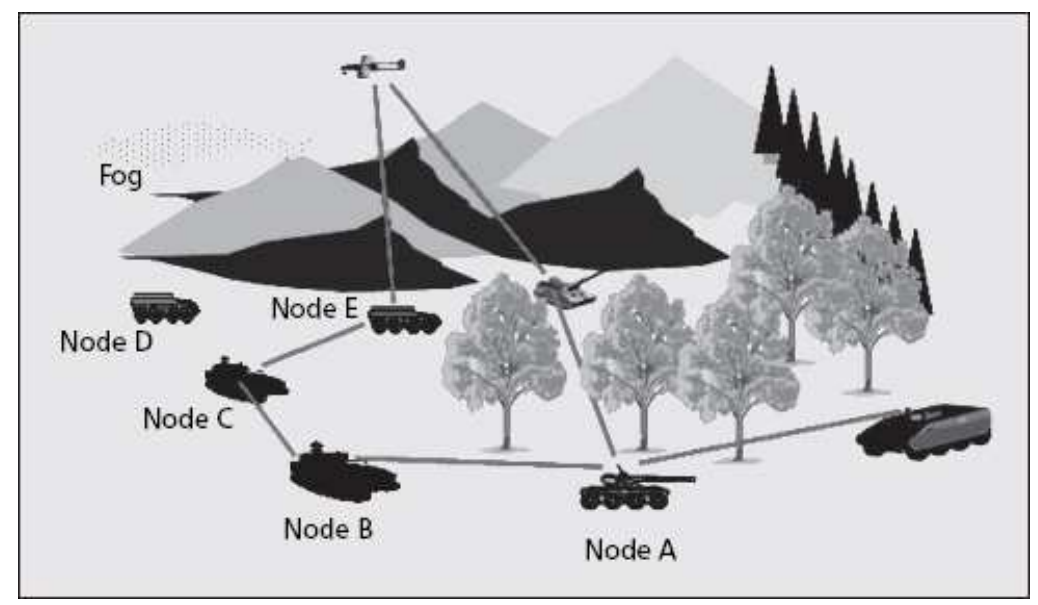

Fig. 19. Topology of a battlefield scenario using FSO system to connect all partners (Juan C. Juarez et al., 2006)

Referring to the picture, node $C$ has two optical heads and must be able to manage the optical beams. Moreover, it is near at the B, D, E nodes; thus node C must be able to take a decision in which direction must point its optical beam. This kind of decision can be managed considering operational aspects; distance from the other devices, rate and traffic demand, distance between the end users, and environment measurement because weather conditions could limit the optical link. In this case, node $C$ is able to send the beam through another path using another nodes. How shown in the picture, node D result isolated because the dense fog does not allow to established a FSO link with the airborne node. Thus, the only way result node $\mathrm{C}$ but its optical heads are both in use. The idea of the optical reconfigurable network is to establish a link between nodes $C$ and D instead of node $B$. Node B will be reached from node.

The quickness in term of time to install, together with a small size, make this kind of technology able to operate in different segments, like for example, the rehabilitation of link in case of terroristic attacks or disaster recovery due to natural catastrophic events (E. Leitgeb et al., 2005).

FSO technology is used also in several non conventional scenarios like: 
- Aerospace communications: a laser beam can directionally guarantee a link between two satellites, between the heart and a satellite platform, and vice versa, without any kind of interference and, at the same time, achieving an high data rate. Several experiments have been performed demonstrating that the FSO technology is mature to accomplish such kind of challenges. On the inter satellite side. In 2008 has been demonstrate an optical link between two LEO orbiting satellites, Terra SAR-X and NFIRE, at 5.5 Gbps on a total distance of $5500 \mathrm{~km}$ and at a speed of $25000 \mathrm{~km} / \mathrm{h}$. On the downstream side. The KIODO (KIrari's Optical Downlink to Oberpfaffenhofen) project demonstrated a downlink stream from the OICETS LEO Japanese satellite. In 2006, 5 trials performed successfully achieving a BER of 10-6 with a modulated optical signal at $50 \mathrm{Mbps}$ and 847nm (N. Perlot et alt, 2007). The FP6 CAPANINA (Communications from Aerial Platform Networks delivering Broadband for ALL) project regarded the downlink between a stratospheric ballon at $22 \mathrm{~km}$ and a transportable ground station in Kiruna, Sweden at $1.25 \mathrm{Gbps}$ (M. Knapex et alt 2006). In 2008 a 2.5 Gbps experiments using a $1 \mathrm{~W}$ laser at $1064 \mathrm{~nm}$ with a BPSK modulation format between a LEO satellite and a ground station has been demonstrated (E. Leitgeb et alt, 2009).

FSO has been also used to establish links between satellites and aircrafts or between aircrafts or even between satellite, aircrafts and ground stations realizing an ad hoc optical broadband wireless airborne network. The LOLA (Liaison Optique Laser Aéroportée) programme, for example, in 2006 demonstrated the first two way FSO link between the ARTEMIS GEO satellite and a Myster 20 airplane flying at $9000 \mathrm{~m}$. At the receiver side an accurate hemispherical broadband pointing system and a CMOS sensor for detection and tracking, with a pointing accurancy better than 1 micron rad, was used (Cazaubiel et alt, 2005). Real time data communications, video and audio, demonstrated via a $50 \mathrm{Mbps}$ transmission with a link acquisition time under the second in 2006 and 2007.

- Deep Space Communications: ultra-long distance can be reached with the FSO system, thanks to the recent developments in this field, in order to allow the link with deep space. A great number of studies investigate about the beam divergence and the geometrical loss to obtain the features to established high data rate FSO link between Earth-Satellite, Earth-Moon, Earth-Mars and Earth to celestial bodies within the solar system. To obtain a detector able to work with very low power, new technologies propose devices such as low noise photon-counting detector tob e placed on the planets in the form of fields array. The link budget description is based on EIRP (effective isotropic radiated power), Space losses and PDE (photodetection efficiency. Furthermore problems can arise from laser to optics coupling and turbulence in high atmosphere if passed. Modulation formats ar based on pulse pattern modulation (PPM), at wavelengths ranging from 1064nm and 1550nm via YDFA technology (D. Caplan et alt, 2007). Dimensioning these parameters, an FSO system can be used for deep space mission since the optical beam can cover large distances and go through the space to reach the destination (Harris Alan et al., 2006). In particular the MLCD project expected performances are 1Mbit/s farthest Mars and $30 \mathrm{Mbit} / \mathrm{s}$ nearest Mars. Increased performances can support data rate up to 1Gbit/s maximum Mars distance, $100 \mathrm{Mbit} / \mathrm{s}$ Jupiter and $10 \mathrm{Mbit} / \mathrm{s}$ Uranus (D. Boroson, C. Chen, B. Edwards, 2005). 
- Undersea communications: FSO is used to transport information from fixed or mobile sea-platforms to other stations without deploying any cable. Using a particular wavelength it is possible to cover small distances (around $100 \mathrm{~m}$ ) but with transmission rate around $10 \mathrm{Mb} / \mathrm{s}$. The disadvantage is that the sea offers an attenuation greater than the attenuations offered by the air. Submarine Laser Communications (SLC) is implemented to achieve high data rate transmissions also in case of emergency between two platforms or between a platform and an airborne system. SLC is used for communication with deeply submerged submarine using an FSO laser at particular wavelength. Often it is used green or blue wavelengths, thus the radiation is placed in visible spectrum. For undersea application, particular type of lasers are used such as xenon chloride $(\mathrm{XeCl})$ laser shifted in the visible spectrum. Each submarine receiver, has the ad-hoc detector to capture the optical laser beam. Several tests was made to study the performances of undersea laser link and also aircraft to submarine transmission system was implemented. An aircraft flying at 40.000 feet was connected with a submarine using a double wavelength: blue wavelength for uplink and green wavelength for the downlink stream. There was also clouds between aircraft and submarine but the detector installed on board of the submarine was able to detect the signal since a special optical receiver was applied. In this way, the use of the blue-green optical wavelength for undersea applications confirmed the use of these optical frequencies in the sea field. The disadvantage of this kind of laser is that its time operational life is not so long; but the technology, today permit to have solid-state lasers. This kind of solution permit to have a longer operational life laser and also with its efficiency is improved. The smaller cost respect to normal gas lasers, permit also the use of these devices in deep space scenario.

- Air to Earth communications: to prolong the band of the RF technology used today for several airplanes carrier to monitor, perform surveillance actions and for GIS (Geographic Information System) applications (Juan C. Juarez et al., 2006). NASA JPL, on this side, demonstrated a 2.5 Gbps FSO link between an UAV and a ground station studying in particular the atmospheric fades and the problems related to the pointing systems (G. Ortiz et alt, 2003).

- Inter island communications: With the DOLCE study, ESA funded project, an inter island free space communication has been demonstrated covering $142 \mathrm{~km}$ between La Palma and Tenerife at $10 \mathrm{Mbps}$ with a 1W MOPA (Master Oscillator Power Amplifier) using a 32 PPM (Pulse Position Modulation) and a simple SiAPD as receiver placed on a OGS (Optical Ground Station) (G. Baister et alt, 2009). On the same link, the ROSA project performed experiments to investigate an optical telemetry system for the mars sample return mission (T. Dreischer, 2008).

- Inter optical communications subsystems: board to board and chip to chip optical wireless interconnections become a reality in the last years (Hirabayashi K. et alt, 1997). The main reasons have been the need to compensate the board to board bottlenecks and to increase the backplane interconnections speed. Especially in chip to chip wireless interconnections, the main problem arise from design and package issues. Other challenges are focused to the development of ultra low driving devices for VCSEL arrays, commonly used in board to board interconnections, and to the increase of alignment tolerance. Experiments demonstrated that is possible to 
establish more than 1000 channels per printed circuit board using a $1 \mathrm{~mm}$ pitch optical beam array having at $1 \mathrm{Gbps}$ per channel, thus a throughput per board up to 1 Tbps (Hirabayashi, Yamamoto, Hino 2004).

\section{Techno economic analysis (Tosi Beleffi - Forin)}

A correct approach, in the techno economic analysis of a FSO based scenario, must focus on the main market drivers that, today, are mainly related to the civil telecommunications. Undersea, inter planetary, inter satellites or military based communications, infact, still are in the research or prototyping field where, everyone knows, the costs are not in principle, especially at the beginning, strictly taken into account for a mass production. This preamble is important to justify the fact that this sub chapter will be mainly devoted to the civil telecommunication applications where the competition of different actors is today increasing the market portfolio thus lowering the overall costs.

The demand for broadband infrastructures, mainly driven today by the request for new multimedia applications, is pushing the Operators to implement specific strategies characterized by a continuous and slow migration to the so called FTTx family (Fiber to The Curb/Cabinet/Building/Home) where the final step is constituted by the FTTH (Fiber To The Home). In the future, infact, is expected that we will have an exact replica of the PSTN network but with fibres instead of the copper. Each end user will have a single or a pair of fibres directly connected with the $\mathrm{CO}$ (Central Office).

Today the main effort is, for what has been previously mentioned, devoted to the development of new burying strategies to lower the CAPEX that, in the fibre optical based infrastructures, are mainly due to the fibre installation. The installation costs of a 36 fibre optical cable, in a typical urban area environment, are, for example, divided between the dig $(12 \%)$, the cable and the cable lying $(14 \%)$ and the civil works for surface footway $(74 \%)$ (A.L.Harmer, 1999). For these reasons a tremendous proliferation of new techniques has been experienced: trench, micro trench, dig, micro dig, one day dig, Teraspan, aerial cables. Several Operators and Municipalities are today performing demo trials to demonstrate the possibility to put the fibre cables in the sewer pipes, inside the urban lighting systems or even in the gas pipes. All these different approaches can, in principle, reduce the installation costs, depending of course on the particular case and/or situation, in average of a $30-40 \%$ respect to a standard trench approach.

But what can happen if must be crossed a river, a railway or connected a neighbour island? In this scenario, which can be the role of the FSO?

It should be considered that nothing is so simple as reported with the pen on the paper. In the case of digs, still many problems are present especially under the regulatory point of view and, most important, for the huge amount of authorizations that has to be requested to the Regions, Provinces, Municipalities and Districts. Is not so simple, costless and fast, infact, taking a excavator and start to dig along a street. On the other side, it must be pointed out that gas pipes, urban lighting systems, sewer pipes, water systems can be in principle used to host optical fibres but still remain critical infrastructures, under the security point of view, and so the fully access to them is still difficult.

We start to understand that the development and the diffusion of the broadband to the end user is not only a matter of digging the fibre. Is a more complex problem where mixed wireless and wired infrastructures can and must coexist. This to limit the digital divide, 
increase the broadband to all, taking care of the costs, both CAPEX and OPEX (Operational Expenditures). Depending on the geography, infact, a particular technology can be better than a different one, being wired or wireless. This open the way to the implementation of mixed infrastructures and to the deployment of different technologies like: WiMax, WiFi, SDH Radio, LMDS, WDCMA/UMTS, UTRAN, GSM, FSO, Satellite, xDLS, Fibre, Coax.

Considering the FSO technology as a point to point based system, we can start to define and differentiate it respect to other possible competitors like the Fibre, the Microwave links, the XDSL and the COAx (see table 5).

\begin{tabular}{|l|l|l|l|l|l|}
\hline & FSO & $\begin{array}{l}\text { Microwave } \\
\text { radio }\end{array}$ & $\begin{array}{l}\text { Optical } \\
\text { Fibre }\end{array}$ & $\begin{array}{l}\text { Coaxial } \\
\text { cable }\end{array}$ & xDSL \\
\hline Speed & Gpbs & Mbps & Independent & Mbps & Mbps \\
\hline Installation & Moderate & Difficult & Difficult & Moderate & Difficult \\
\hline Uses & $\begin{array}{l}\text { P2P/P2MP } \\
\text { short and } \\
\text { long reach }\end{array}$ & $\begin{array}{l}\text { P2P short } \\
\text { reach }\end{array}$ & $\begin{array}{l}\text { P2P/P2MP } \\
\text { short and } \\
\text { long reach }\end{array}$ & $\begin{array}{l}\text { Campus, } \\
\text { multi } \\
\text { drop } \\
\text { short } \\
\text { reach }\end{array}$ & $\begin{array}{l}\text { Phone and } \\
\text { data, access } \\
\text { telecom } \\
\text { sector }\end{array}$ \\
\hline Advantages & $\begin{array}{l}\text { Price vs } \\
\text { performances, } \\
\text { security }\end{array}$ & $\begin{array}{l}\text { Speed vs } \\
\text { installation }\end{array}$ & $\begin{array}{l}\text { Huge } \\
\text { Available } \\
\text { bandwidth, } \\
\text { security }\end{array}$ & $\begin{array}{l}\text { Better } \\
\text { than } \\
\text { other } \\
\text { copper } \\
\text { media. }\end{array}$ & $\begin{array}{l}\text { Low cost, is } \\
\text { already } \\
\text { present. }\end{array}$ \\
\hline Disadvantages & $\begin{array}{l}\text { Dependent on } \\
\text { the climatic } \\
\text { conditions }\end{array}$ & $\begin{array}{l}\text { Can be } \\
\text { intercepted }\end{array}$ & $\begin{array}{l}\text { Installation } \\
\text { costs }\end{array}$ & $\begin{array}{l}\text { Costs } \\
\text { limited by } \\
\text { interference } \\
\text { and cable } \\
\text { quality }\end{array}$ \\
\hline Security & Good & Poor & Very good & Good & Good \\
\hline Maintenance & Low & Low & Low & Moderate & High \\
\hline Skills & Moderate & High & High & Moderate & Moderate \\
\hline
\end{tabular}

Table 5. Comparison between different P2P networks

From table 5 we can start to figure out, respect to other P2P technologies, the sector of influence that can be covered by the FSO technology. In order to understand which broadband technology can be the most efficient in terms of CAPEX and OPEX, we have to go deeper in the problem considering also the following economic factors like: cost per line, average return per user, mean time before failure (MTBF), mean time to repair (MTTR), warranty by vendor, upgradable characteristics, operation and maintenance costs, manufactured respect to which standard.

Going deeper and deeper in the analysis we can make a simple calculation pointing out the main media/devices needed to set up a point to point link (see Table 6). In this case we can see that the main characteristics of a point to point optical wireless link are to be wideband, easy and fast to install as well as low cost respect to the other technologies. The mix made by cost per bandwidth per easy to use/install is the winner. The main drawback is of course due to the climatic conditions encountered that limit, in case, the maximum distance/bit rate achievable. Adding a RF (Radio Frequency) link, increases the costs but increases also the availability. 


\begin{tabular}{|c|c|c|c|}
\hline TECHNOLOGY & MAIN COSTS & LICENCES & NOTES \\
\hline FSO & $\begin{array}{l}\text { From } 13 \mathrm{k} € @ 155 \mathrm{Mbps} \text { to } \\
19 \mathrm{k} € \text { @ } 1.2 \mathrm{Gbps} \text { (up to } 3.6 \\
\mathrm{~km} \text { ). From } 22 \mathrm{k} € @ 155 \mathrm{Mbps} \\
\text { (up to } 5.7 \mathrm{~km} \text { ) to } 33 \mathrm{k} € \text { @ } 1.2 \\
\text { Gbps (up to } 5.3 \mathrm{~km} \text { ) (source: } \\
\text { vendor). }\end{array}$ & $\begin{array}{l}\text { Is not needed a } \\
\text { licence. An una } \\
\text { tantum per year is } \\
\text { due to the reference } \\
\text { / control PA. }\end{array}$ & $\begin{array}{l}\text { Fast installation both } \\
\text { indoor and outdoor. } \\
\text { Radio backup is needed } \\
\text { to increase the } \\
\text { availability up to } \\
99.999 \% \text {. }\end{array}$ \\
\hline RF & $\begin{array}{l}\text { From } 20 \mathrm{k} € \text { to } 30 \mathrm{k} € \text { depending } \\
\text { on the length }(1-10 \mathrm{~km}) \\
\text { working @ } 18,26 \text { or } 38 \mathrm{GHz} \\
\text { can transmit up to } 300 \mathrm{Mbps} \text {. } \\
\text { (source: vendor). }\end{array}$ & $\begin{array}{l}\text { Is needed a licence. } \\
\text { Example: For } \\
28 \mathrm{MHz} \text { in the } 7 \mathrm{GHz} \\
\text { bandwidth along } \\
20 \mathrm{~km} \text { costs around } \\
5 \mathrm{k} € \text {. (source: PA) }\end{array}$ & $\begin{array}{l}\text { Fast installation, limited } \\
\text { bandwdith. High time } \\
\text { window if is considered } \\
\text { the time needed to have } \\
\text { the licence. }\end{array}$ \\
\hline FIBRE & $\begin{array}{l}\text { In the case of a P2MP system } \\
\text { that is the most cost effective } \\
\text { in terms of CAPEXs respect to } \\
\text { a pure FTTH. A standard } \\
\text { GPON OLT (with } 4 \text { G- } \\
\text { Ethernet ports), a 1:16 splitter, } \\
\text { an ONU serving } 48 \text { VDSL2 } \\
\text { end users, } 15 \text { ONTs with } 2 \\
\text { GEthernet ports and VOIP } \\
\text { [Everything compliant with } \\
\text { the ITU G.984 standard] has a } \\
\text { total cost of around } 26 \mathrm{k} € \text {. } \\
\text { (Source: vendor). } \\
\text { Around } 70 € / m \text { for the dig } \\
\text { and } 10 € / m \text { for the cable in } \\
\text { urban environment. In river } \\
\text { basin the installation plus the } \\
\text { cable (120 fibres) can go down } \\
\text { at around } 16 € / m \text {. (Source: } \\
\text { PA). }\end{array}$ & $\begin{array}{l}\text { Dark fibres can be } \\
\text { rented in average } \\
\text { from } 5 \text { to } 15 € / \mathrm{m} \\
\text { with a } 15 \text { year } \\
\text { based contract } \\
\text { (source: consulting } \\
\text { center). Free ducts } \\
\text { can be also rented } \\
\text { at around } 12,3 € / \mathrm{m} \\
\text { (source: company). }\end{array}$ & $\begin{array}{l}\text { Slow installation, dig is } \\
\text { needed with or without } \\
\text { trench. The bandwidth } \\
\text { is virtually unlimited. } \\
\text { Today the new dig } \\
\text { techniques can lower } \\
\text { the costs up to } 40 \% \\
\text { depending on several } \\
\text { factors. (source: } \\
\text { operator) }\end{array}$ \\
\hline$x \mathrm{xSL}$ & $\begin{array}{l}\text { The costs can vary from } 14 \mathrm{k} € \\
\text { for an IP DSLAM serving } 64 \\
\text { users (modems included) up } \\
\text { to } 40 \mathrm{k} € \text { for an IP DSLAM } \\
\text { serving up to } 1024 \text { end users } \\
\text { (modem included). In this last } \\
\text { case the average bit/ rate per } \\
\text { client is at around 10-15 Mbps } \\
\text { over } 1.2 \mathrm{~km} \text { - access network } \\
\text { segment. (Source: consulting } \\
\text { center). }\end{array}$ & $\begin{array}{l}\text { Copper line/client } \\
\text { in unbundling } \\
\text { regime is in } \\
\text { average at } 7,5 € \\
\text { (source: operator). } \\
\text { A twisted pair can } \\
\text { vary from } 80 € \text { to } \\
225 € \text { depending on } \\
\text { the cable quality. } \\
\text { (source: operator). } \\
\text { Installation costs } \\
\text { are in average at } \\
80-85 € / m \text {. (source: } \\
\text { consulting center). }\end{array}$ & $\begin{array}{l}\text { Maximum available } \\
\text { bandwid is limited by } \\
\text { intereferences. Major } \\
\text { costs due to copper } \\
\text { maintenance Other } \\
\text { voices (COapparatus } \\
\text { rental, CO apparatus } \\
\text { maintenance, et alt). }\end{array}$ \\
\hline
\end{tabular}

Table 6. Main costs per technology. All these costs do not include installation\&maintenance.

It can be also pointed out that, especially where the duct availability is limited, FSO can provide an economically favourable alternative to both FTTH/FTTC scenarios (T. Rokkas et 
alt, 2007). Using a particular tool originated from several EU projects (IST-TONIC TechnOecoNomICs of IP optimised networks and services, and the CELTIC ECOSYS TechnoECOnomics of integrated communication SYStems and services), a geometric area model has been obtained to calculate the number of network elements required (Cabinet, Local Exchange, Central Office, Fiber Cables) to reach the end user premise. Based on this geometric area, taking a MTBF of 10 years and a MTTR of $8 \mathrm{~h}$ and considering the duct availability, has been demonstrated a Net Present Value (NPV) for FSO Local Exchange (LE) better than FTTC and FTTH, in case of no duct availability. The fibre based scenarios are better that the FSO LE building alternative if the duct availability is greater than $70 \%$ (T.Rokkas et Alt, 2007).

Last but not least, analizing the world market from the very beginning is interesting to see that in principle the society consider, in general, communications not as a fad but as a necessity. The global consumption of fiber optic components in communication networks exploded from only $2.5 \$$ million in 1975 to $15.8 \$$ billion in 2000 (J.D. Montgomery, 1999). Continued growth to $739 \$$ billion in 2025 is expected. In particular, from 2000 to 2025, the average annual growth rate has been predicted (J.D. Montgomery, 1999), not considering the actual negative conjuncture, to $12 \%$ for fiber optic cable, $21 \%$ for active components, $19 \%$ for passive components, $15 \%$ for other components. Analyzing data more close to the current time period we can outline that the global fiber optic connector and mechanical splice consumption in 2006 was $\$ 1.401$ billion and by the year 2011, the worldwide consumption value is forecasted to reach $\$ 3.462$ billion (ElectroniCast, 2008). Fiber optic collimating lenses market in Japan/pacific Rim lead the global consumption (number of units used) with $46.7 \%, 37.9 \%$ in North America. Europe with a market share close to $15 \%$ is forecasted to experience a flat growth trend considering the manufacturing outsourcing strategies. Fiber optic collimating lens assemblies market in North America lead the global consumption volume (number of units used) with 40\%, 35\% in Japan Pacific Rim. Europe is forecasted to increase due to the value-added building of sub assemblies and equipment (ElectroniCast, 2008). Furthermore, the laser product market continued to expand at a healthy rate in 2008 with fiber laser sales almost reached $\$ 300$ million in revenue (Strategies Unlimited, 2009). Bank of America forecast $21 \%$ growth in 2010 for the semiconductor market mainly driven by electronic equipment sales. Global electronic equipment revenue will rise by $4.9 \%$ in 2010 after a $9.8 \%$ decline in 2009, respect to 2008, while the global semiconductor revenue is set to loose $23 \%$ in 2009 respect to 2008 (D. Manners, 2009). It must be pointed out that, in this case, the main electronic equipment categories are: automotive, data processing, wired communications, wireless communications, consumer and industrial. The automotive decline from 2008 to 2009 had a major impact on the overall electronic equipment sales.

Analyzing the data, it can be affirmed that despite the global crisis, the telecom market is holding up the shock and is representing a real answer for the Governments. Focusing the telecom sector, especially in the part related to FSO technologies/components, all the data analyzed demonstrate a good vitality with both capital expenditures, consumes and revenues. On this point it is expected from GE and 10GE technology to be the next driver for the FSO companies. 10 Gbps Ethernet lines becomes reality not only within campus or high rise networks but also to all that customers involved in applications like redundant data centres, medical imaging and HDTV editing. The costs of 10G FSO systems will certainly tied by the adoption of the 10GE technology and by it corresponding decrease in the cost curve. The trade-off for the 10G FSO will be, for example, from the receiver side point of 
view on the balance between the size/sensitivity of the InGaAs receivers (suitable at 1550nm) and the tracking/focusing system. FEC, DWDM, laser driver and preamplifiers at the receiver will certainly must be taken into account to accomplish an economy of scale for 10G FSO (I. Kim, 2009).

\section{Conclusion (All)}

Communications and transmissions are two fundamental concepts that follow the human being from the beginning. Free Space Optics is only one of the several choices that we have today in the complex and mixed telecommunication environment (WiFi, WiMax, LTE, Fibre, Coax, GSM, UMTS, et alt). With its inherent carachteristics like ease of installation, fast ROI, low CAPEX, intrinsic security, broad band and with its wide applications range, from under sea to deep space, free space optics represents today a solution that all the telecom actors have to take into account. Especially now that 10/100 GEthernet technology is appearing at the horizon.

\section{References}

F. Nadeem, B. Geiger, E. Leitgeb, M. S. Awan, S. S. Muhammad, M. Loeschnig, and G. Kandus (2009) Comparison of link selection algorithms for fso/rf hybrid network, IET, submitted 2009.

I. Kim (2009) 10G FSO systems position technology for the future, Ligthwave, PennWell July 2009.

L. Stotts, L. Andrews, P. Cherry, J. Foshee, P. Kolodzy, W. McIntire, M. Northcott, R. Phillips, H. Pike, B. Stadler, and D. Young (2009) Hybrid optical rf airborne communications, Proceedings of the IEEE, vol. 97, no. 6, pp. 1109-1127, June 2009.

E. Leitged, M.S. Awan, P. Brandl, T. Plank, C. Capsoni, R. Nebuloni, T. Javornik, G. Kandus, S. Sheik Muhammad, F. Ghassenlooy, M. Loschnigg, F. Nadeem (2009) Current Optical Technologies for wireless access, Proc. Of IEEE CONTEL Conference, Zagreb Croatia 8-10 June 2009.

J. Wells (2009), Faster than fiber, IEEE Microwave Magazine, vol. 10, no. 3, pp. 104-112, May 2009.

F. Nadeem, B. Geiger, M. S. Awan, E. Leitgeb, and G. Kandus (2009) Evaluation of switch-over methods for hybrid FSO-WLAN systems, in Wireless VITAE, Aalborg, May 2009, pp. 565-570.

F. Nadeem, B. Geiger, M. Henkel, E. Leitgeb, M. S. Awan, M. Gebhart, S. Hranilovic, and G. Kandus (2009) Comparison of wireless optical communication availability data and traffic data, in VTC Spring, Barcelona, April 2009, pp. 1-5.

F. Nadeem, B. Geiger, M. Henkel, E. Leitgeb, M. Löschnig, and G. Kandus (2009) Switch-over implementation and analysis for hybrid wireless network of optical wireless and GHz links, in WTS, Prag, April 2009, pp. 1-6.

F. Nadeem, M. Henkel, B. Geiger, E. Leitgeb, and G. Kandus (2009) Implementation and analysis of load balancing switch over for hybrid wireless network, in WCNC, Budapest, April 2009, pp. 1-6.

G. Baister, K. Kudielka, T. Dreischer, M. Tüchler (2009), "Results from the DOLCE (Deep Space Optical Link Communications Experiment) Project", Proc. of SPIE Vol. 7199 71990B-1.

D. Manners (2009) Semiconductor sales to grow 10\% in Q3, says iSuppli, ElectroncsWeekly.com 
Strategies Unlimited (2009) Fiber and industrial Laser Market review and forecast, OM-46 Third Edition 2009.

S. Bloom andW. S. Hartley (2009), The last-mile solution: hybrid FSO radio, http://www.systemsupportsolutions.com/whitepapers.htm.

ElectroniCast (2008) Fiber Optic Connector and Mechanical Splice Global Market E Technology Forecast (2007-2012), Global Summary.

ElectroniCast (2008) Fiber Optic Communication Collimator Lens \& Lens assemblies global market forecast (2007-2012), Global Summary.

T. Dreischer, "ROSA Final Presentation (RF-Optical System Study for Aurora)", ESA Contract No. 20371/07/NL/EK Final Presentation, ESTEC, 2nd December 2008

S. Gurumani, H. Moradi, H. H. Refai, P. G. LoPresti, and M. Atiquzzaman (2008) Dynamic path reconfiguration among hybrid fso/rf nodes, in GLOBECOM, November 2008, pp. 1-5.

M. S. Awan, E. Leitgeb, S. S. Muhammad, Marzuki, F. Nadeem, M. S. Khan, and C. Capsoni, Distibution function for continental and maritime fog environments for optical wireless communication, in CSNDSP, July 2008, pp. 260-264.

J. Pacheco de Carvalho, H. Veiga, P. Gomes, and A. Reis (2008) Experimental development and study of Wi-Fi and FSO links, in CSNDSP, July 2008, pp. 137-141.

V. Kvicera, M. Grabner, and O. Fiser (2008) Visibility and attenuation due to hydrometeors at 850 $n m$ measured on an 850 m path, in CSNDSP, July 2008, pp. 270-272.

A. Chaman Motlagh, V. Ahmadi, Z. Ghassemlooy, and K. Abedi (2008) The effect of atmospheric turbulence on the performance of the free space optical communications, in CSNDSP, July 2008, pp. 540-543.

R. Nebuloni and C. Capsoni (2008) Laser attenuation by falling snow in CSNDSP, July 2008, pp. 265-269.

H. Alma and W. Al-Khateeb (2008) Effect of weather conditions on quality of free space optics links (with focus on malaysia) in ICCCE, May 2008, pp. 1206-1210.

A.K. Majumdar, J.C.Ricklin (2008) Free Space Laser Communications Principles and Advances, Springer ISBN 978-0-387-28652-5.

S. Vangala and H. Pishro-Nik (2007) A highly reliable fso/rf communication system using efficient codes, in Global Telecommunications Conference, 2007. GLOBECOM '07. IEEE, Nov. 2007, pp. 2232-2236.

D. Caplan, M. Stevens, B. Robinson, S. Constrantine, D. Boroson Ultra-Long Distance Free Space Laser Communications, CLEO Conference 2007, Baltimore USA.

Perlot, N. et al, "Results of the Optical Downlink Experiment KIODO from OICETS Satellite to Optical Ground Station Oberpfaffenhofen (OGSOP)", Proceedings of SPIE, Vol. 6457, 2007.

T. Rokkas, T. Kamalikis, D. Katsianis, D. Varoutas and T. Sphicopoulos (2007), FBusiness prospects of wide-scale deployment of free space optical technology as a last mile solution: a techno-economic evaluation, Journal of Optical Networking Vol.6 No.7, July 2007.

S. Vangala and H. Pishro-Nik (2007) Optimal hybrid RF-wireless optical communication for maximum efficiency and reliability, in CISS, March 2007, pp. 684-689.

Markus Knapek, Joachim Horwatha, Nicolas Perlota, Brandon Wilkersonb (2006) The DLR Ground Station in the Optical Payload Experiment (STROPEX) - Results of the Atmospheric Measurement Instruments, Proc of SPIE, ISSN 0277-786X CODEN PSISDG. 
Harris Alan, Sluss James J., Refai Hazem H., Lopresti Peter G., (2006). Analysis of beam steering tolerances and divergence for various long range FSO communication links, proceedings of SPIE, the international Society for Optical Engineering, ISSN 0277786X.

Juan C. Juarez, Anurag Dwivedi, A. Roger Hammons, Steven D. Jones, Vijitha Weerackody, Robert A. Nichols, (2006). Free-Space Optical Communications for Next-Generation Military Networks, IEEE Communications Magazine, November 2006.

M. Abtahi and L. Rusch (2006) Mitigating of scintillation noise in FSO communication links using saturated optical amplifiers, in MILCOM, October 2006, pp. 1-5.

E. Leitgeb, S. S. Muhammad, B. Flecker, C. Chlestil, M. Gebhart, and T. Javornik (2006) The influence of dense fog on optical wireless systems, analysed by measurements in Graz for improving link-reliability, in ICTON, July 2006, pp. 154-159.

B. Flecker, M. Gebhart, E. Leitgeb, S. S. Muhammad, and C. Chlestil (2006) Results of attenuation-measurements for optical wireless channel under dense fog conditions regarding different wavelengths, in SPIE, 2006, pp. 1-11.

Cazaubiel, V. et al., "Le terminal optique aeroporte sur lola", Proceedings of OPTRO 2005 Conference, Paris, France, May 2005

Don M Boroson, Chien-Chung Chen, Bernard Edwards Overview of the Mars Laser Communications Deminstration Project, IEEE LEOS Vol 19 N.5 Oct. 2005.

D. Grace, M. Mohorcic, M. H. Capstick, M. Bobbio Pallavicini, M. Fitch (2005) Integrating Users into the Wider Broadband Network via High Altitude Platforms, IEEE Wireless Communications, Vol. 12, No. 5, October 2005.

J. Derenick, C. Thorne, and J. Spletzer (2005), On the deployment of a hybrid free-space optic/radio frequency (FSO/RF) mobile ad-hoc network, in IROS, August 2005, pp. 39903996.

T. Kamalakis, I. Neokosmidis, A. Tsipouras, T. Sphicopoulos, S. Pantazis, and I. Andrikopoulos (2005) Hybrid free space optical/millimeter wave outdoor links for broadband wireless access networks, in PIMRC, 2005, pp. 1-5.

CAPANINA project website www.capanina.org 2005

Arun K. Majumdar and Jennifer C. Ricklin, (2005). Free-Space laser communication performance, principles and advantages, pp.9-56, Springer, New York, 2005.

E. Leitgeb, S. S. Muhammad, C. Chlestil, M. Gebhart, and U. Birnbacher (2005) Reliability of FSO links in next generation optical networks, in ICTON, July 2005, pp. 394-401

Osorio, José Alberto Huanachín Osorio (2005) Simulação e desenvolvimento de um enlace de "Free-Space Optics" no Rio de Janeiro e a relação com a ITU-T G826, Master Thesis, PUC - Rio de Janeiro, 2005.

S. S. Muhammad, P. Köhldorfer, and E. Leitgeb (2005) Channel modeling for terrestrial free space optical links, in ICTON, July 2005, pp. 407-410.

A. Akbulut, H. Ilk, and F. Ari (2005) Design, availability and reliability analysis on an experimental FSO/RF communication system, in ICTON, July 2005, pp. 403-406.

ITU (2005) Attenuation due to clouds and fog, recommendation ITU-R P840-3.

E. Leitgeb, S. Sheikh Muhammad, M. Gebhrt, Ch. Chlestil, U. Birnbacher, O. Koudelka, P. Schrotter, A. Merdonig, Gorazd Kandus, (2005). Hybrid wireless networks combining WLAN, FSO and satellite technology for disaster recovery, Proceedings of 14th IST Mobile \& Wireless Communications Summit, Dresden, Germany, 19-23 June 2005. (COBISS.SI-ID19153703). 
S. Bloom (2005) The physics of free-space optics, May 2005, white Paper, Air Fiber.

H. Wu, B. Hamzeh, and M. Kavehrad (2004) Achieving carrier class availability of FSO link via a complementary RF link, in ACSSC, November 2004, pp. 1483-1487.

S. Hashmi and H. Mouftah (2004) Integrated optical/wireless networking, in Electrical and Computer Engineering, 2004. Canadian Conference on, vol. 4, May 2004, pp. 20952098 Vol.4.

E. Leitgeb, M. Gebhart, U. Birnbacher, W. Kogler, and P. Schrotter (2004) High availability of hybrid wireless networks, Proceedings of the SPIE, vol. 5465, pp. 238-249, 2004

Hirabayashi K., Yamamoto T., Hino S. (2004) Optical backplane with free-space optical interconnections using tunable beam deflectors and a mirror for bookshelf-assembled terabit per second class asynchronous transfer mode switch, Optical Engineering 37(2004), pp 1332-1342, Donal O'Shea Ed.

S. D. Milner and C. C. Davis (2004), Hybrid free space optical/RF networks for tactical operations, in MILCOM, 2004, pp. 409-415.

H. Izadpanah, T. ElBatt, V. Kukshya, F. Dolezal, and B. K. Ryu (2003) High-availability free space optical and RF hybrid wireless networks, IEEE Wireless Communications, pp. 4553, April 2003.

W. Kogler, P. Schrotter, U. Birnbacher, E. Leitgeb, and O. Koudelka (2003), Hybrid wireless networks - high availability with combined optical / microwave links, in Telecommunications and Mobile Computing, Mar. 2003, pp. 1-3.

Ortiz, G.G. et al, "Design and development of robust ATP subsystem for the Altair UAV-to-ground lasercomm 2.5-Gbps demonstration", Proceedings of the SPIE Vol. 4975, 2003.

A.A. Huurdeman, (2003). The worldwide history of telecommunications John Wiley \& Sons ISBN 0-471-20500-2

A Paulo S. B. André, António L. J. Teixeira, João L. Pinto (2003) Simulation of Laser Beam Propagation Through the Atmosphere for Optical Communications Proposes, Proceedings of ConfTele 2003, Portugal.

Zhu, Xiaming Zhu, Joseph M. Kahn (2002) "Free-Space Optical Communication Through Atmospheric Turbulance Channels", IEEE Transactions on Communications, vol. 50, pp. 1293-1300, August 2002.

J. Tanczos (2002) Untersuchungen der Verfügbarkeit optischer Freiraumübertragungsstrecken, Master's thesis, Technical University of Graz, 2002.

T. ElBatt and H. Izadpanah (2001) Design aspects of hybrid rf/free space optical wireless networks, in Broadband Communications for the Internet Era Symposium digest, 2001 IEEE Emerging Technologies Symposium on, 2001, pp. 157-161.

Almeida, Rui Sérgio Rainho de Almeida, José Luís de Jesus Ferreira Santo (2001) Sistemas de Transmissão/Recepcção sem fios por Raios Infravermelhos, University of Aveiro, Aveiro, Portugal, Graduation Project, 2001.

B. Bova, S. Rudnicki, (2001). The Story of Light, Sourcebook ISBN 1-4022-0009-9

I. I. Kim and E. Korevaar (2001) Availability of free space optics (FSO) and hybrid FSO/RF systems, http:/ / www.freespaceoptic.com/WhitePapers/SPIE2001b.pdf.

J.D. Montgomery (1999) Fifty year of fiber optics, Nasua, N.H. Lightwave/Penn Well Corp.

A.L.Harmer, (1999) Communication cables and related technologies, IOS Press, EuroCable 1999, p.170. 
Strickland, Brian R. Strickland, Michael J. Lavan, Eric Woodbridge, Victor Chan (1999) Effects of fog on the bit-error rate of a free-space laser communication system, Applied Optics, vol. 38, pp. 424-431, January 1999.

Kim, Isaac I. Kim, Eric Woodbridge, Victor Chan, Brian R. Strickland (1998) Proceedings of SPIE, vol. 3266, pp. 209-220, 1998.

T. Carbonneau and D. Wisley (1998) Opportunities and challenges for optical wireless; the competitive advantage of free space telecommunications links in today's crowded market place, in SPIE Conference on Optical Wireless Communications, 1998, pp. 119-128.

Hirabayashi K., Yamamoto T., Hino S.Kohama Y., Tateno K. (1997) Optical beam direction compensating system for board-to-board free space optical interconnection in high-capacity ATM switch, Journal of Lightwave technology Vol15, N.5, pp.874-882.

Kim, Isaac I. Kim, Harel Hakakha, Prasanna Adhikari, Eric Korevaar, Arun K. Majumbar (1997) Scintillation reduction using multiple transmitters, Proceedings of SPIE, vol. 2990, pp. 102-113, 1997.

Wichel, Hugo Weichel (1990) Laser Beam Propagation in the Atmosphere, Washington: Tutorial Texts, 1990.

Clifford, S. F. Clifford, R. J. Hill (1981) Relation between irradiance and log-amplitude variance for optical scintillation described by the K distribution, Journal of the Optical Society of America A, vol. 71, pp. 1112-114, January 1981.

Strohbehn, J. W. Strohbehn ed., (1978) Laser Beam Propagation in the Atmosphere New York: Springer-Verlag, 1978.

G. Pottino, (1976). I Cartaginesi in Sicilia Palermo, Italy.

Unknown, (1968) Da Trastevere alla Colombo le telefonare del futuro, Column on "Il Messaggero", Italian National Newspaper, 11 June 1968 Rome, Italy.

E.Kube, (1968). Information Transmission by light beams through the atmosphere, Journal Nachrichtentechnik 19 (1969) II.6

A.R.Michaelis, (1965). From Semaphore to Satellite, International Telecommunication Union, Geneva, p.18.

G.Agnello, (1963). Le torri costiere di Siracusa nella lotta anticorsara Archivio storico di Siracusa, Vol I-IV, p.25, Siracusa, Italy.

V. Castelli, (1700). Dizionario enciclopedico siculo, B.C. Palermo, Italy

Eschilo, (458 b.C.). Orestea (Agamennone-Coefore.Eumenidi), prol. 15-30. 


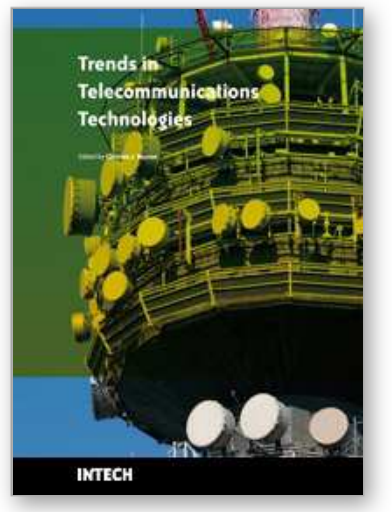

\author{
Trends in Telecommunications Technologies \\ Edited by Christos J Bouras
}

ISBN 978-953-307-072-8

Hard cover, 768 pages

Publisher InTech

Published online 01, March, 2010

Published in print edition March, 2010

The main focus of the book is the advances in telecommunications modeling, policy, and technology. In particular, several chapters of the book deal with low-level network layers and present issues in optical communication technology and optical networks, including the deployment of optical hardware devices and the design of optical network architecture. Wireless networking is also covered, with a focus on WiFi and WiMAX technologies. The book also contains chapters that deal with transport issues, and namely protocols and policies for efficient and guaranteed transmission characteristics while transferring demanding data applications such as video. Finally, the book includes chapters that focus on the delivery of applications through common telecommunication channels such as the earth atmosphere. This book is useful for researchers working in the telecommunications field, in order to read a compact gathering of some of the latest efforts in related areas. It is also useful for educators that wish to get an up-to-date glimpse of telecommunications research and present it in an easily understandable and concise way. It is finally suitable for the engineers and other interested people that would benefit from an overview of ideas, experiments, algorithms and techniques that are presented throughout the book.

\title{
How to reference
}

In order to correctly reference this scholarly work, feel free to copy and paste the following:

Davide M. Forin, G. Incerti, G.M. Tosi Beleffi, A.L.J. Teixeira, L.N. Costa, P.S. De Brito Andre, B. Geiger, E. Leitgeb and F. Nadeem (2010). Free Space Optical Technologies, Trends in Telecommunications Technologies, Christos J Bouras (Ed.), ISBN: 978-953-307-072-8, InTech, Available from: http://www.intechopen.com/books/trends-in-telecommunications-technologies/free-space-optical-technologies

\section{INTECH}

open science | open minds

\section{InTech Europe}

University Campus STeP Ri

Slavka Krautzeka 83/A

51000 Rijeka, Croatia

Phone: +385 (51) 770447

Fax: +385 (51) 686166

www.intechopen.com

\section{InTech China}

Unit 405, Office Block, Hotel Equatorial Shanghai

No.65, Yan An Road (West), Shanghai, 200040, China

中国上海市延安西路65号上海国际贵都大饭店办公楼 405 单元

Phone: +86-21-62489820

Fax: +86-21-62489821 
(C) 2010 The Author(s). Licensee IntechOpen. This chapter is distributed under the terms of the Creative Commons Attribution-NonCommercialShareAlike-3.0 License, which permits use, distribution and reproduction for non-commercial purposes, provided the original is properly cited and derivative works building on this content are distributed under the same license. 